Manuscript 187249P

LBNL-48860

FRACTURE AND FATIGUE BEHAVIOR AT AMBIENT AND ELEVATED TEMPERATURES OF ALUMINA BONDED WITH COPPER/NIOBIUM/COPPER INTERLAYERS

\author{
J. J. Kruzic, R. A. Marks, M. Yoshiya ${ }^{\dagger \dagger}$, A. M. Glaeser, R. M. Cannon, and \\ R. O. Ritchie \\ Materials Sciences Division, Lawrence Berkeley National Laboratory \\ and \\ Department of Materials Science and Engineering, \\ University of California, Berkeley, CA 94720, USA \\ ${ }^{\top}$ Currently at Materials Research and Development Laboratory, Japan Fine Ceramics Center, 2-4- \\ 1 Mutsuno, Atsuta, Nagoya 456-8587, Japan
}

Rev. July 2002

submitted to

Journal of the American Ceramic Society

Work supported by the Director, Office of Science, Office of Basic Energy Sciences, Division of Materials Sciences and Engineering of the U.S. Department of Energy under Contract No. DE-AC03-76SF00098. 


\title{
FRACTURE AND FATIGUE BEHAVIOR AT AMBIENT AND ELEVATED TEMPERATURES OF ALUMINA BONDED WITH COPPER/NIOBIUM/COPPER INTERLAYERS
}

\author{
J. J. Kruzic, R. A. Marks, M. Yoshiya ${ }^{+\dagger}$, A. M. Glaeser ${ }^{*}$, R. M. Cannon ${ }^{*}$, and R. O. Ritchie \\ Materials Sciences Division, Lawrence Berkeley National Laboratory, and \\ Department of Materials Science and Engineering, \\ University of California, Berkeley, CA 94720
}

\begin{abstract}
Interfacial fracture toughness and cyclic fatigue-crack growth properties of joints made from 99.5\% pure alumina partial transient-liquid phase bonded using copper/niobium/copper interlayers have been investigated at both room and elevated temperatures, and assessed in terms of interfacial chemistry and microstructure. The mean interfacial fracture toughness, $G_{\mathrm{c}}$, was found to decrease from 39 to $21 \mathrm{~J} / \mathrm{m}^{2}$ as temperature was raised from $25^{\circ}$ to $1000^{\circ} \mathrm{C}$, with failure primarily at the alumina/niobium interfaces. At room temperature, cyclic fatigue-crack propagation occurred at both the niobium/alumina interface and in the alumina adjacent to the interface, with the fatigue threshold, $\Delta G_{\mathrm{TH}}$, ranging from $20-30 \mathrm{~J} / \mathrm{m}^{2}$; the higher threshold values in that range resulted from a predominantly near-interfacial (alumina) crack path. During both fracture and fatigue failure, residual copper at the interface deformed and remained adhered to both sides of the fracture surface, acting as a ductile second phase, while separation of the niobium/alumina interface appeared relatively brittle in both cases. The observed fracture and fatigue behavior is considered in terms of the respective roles of the presence of ductile copper regions at the interface which provide toughening, extrinsic toughening due to grain bridging during crack propagation in the alumina, and the relative crack propagation resistance of each crack path, including the effects of segregation at the interfaces found by Auger spectroscopy.
\end{abstract}

\footnotetext{
${ }^{+}$Currently at Materials Research and Development Laboratory, Japan Fine Ceramics Center, 2-4-1 Mutsuno, Atsuta, Nagoya 456-8587, Japan

${ }^{\dagger}$ Member, American Ceramic Society

${ }^{*}$ Fellow, American Ceramic Society

Supported by the Director, Office of Science, Office of Basic Energy Sciences, Division of Materials Sciences and Engineering, the U.S. Department of Energy under Contract No. DE-AC03-76SF00098.
} 


\section{Introduction}

If ceramics are to reach their potential as high temperature structural materials, then practical and reliable joining processes must be developed. Partial transient liquid-phase (PTLP) bonding ${ }^{1-}$ ${ }^{11}$ is one potential avenue towards this goal, offering lower processing temperatures and/or pressures than conventional diffusion bonding while providing joints that can retain appreciable strength at elevated temperatures.

One model system used to further the understanding of PTLP methods employs a relatively thicker niobium core layer with thin $(<5 \mu \mathrm{m})$ copper cladding layers to bond alumina. ${ }^{5,6,9}$ During bonding, the liquid copper-rich phase de-wets the interface, yielding two distinct metallic phases in contact with the alumina, one niobium-rich and the other copper-rich. Although discrete copper-rich particles persist along the interface and melt at $\sim 1083^{\circ} \mathrm{C}$, the high area fraction of niobium/alumina contact allows joints to retain reasonably high strength levels up to $1300^{\circ} \mathrm{C}$, well above the melting point of copper, with the majority of failures occurring away from the joint in the alumina. ${ }^{5,6}$ While strength is an important property governing the suitability of joints for structural applications, fracture and cyclic fatigue properties (i.e., flaw tolerance) must also be assessed to predict the reliability and lifetime of joints. To our knowledge, no previous studies have investigated the fracture toughness and fatigue-crack growth properties at or near PTLP bonded joints. Accordingly, the present work presents a first investigation of the fracture and cyclic fatigue properties of PTLP bonded joints at both ambient and elevated temperatures for the model system of alumina bonded with copper/niobium/copper interlayers. Results can be compared to fracture toughness behavior that has been reported for a variety of niobium/alumina samples prepared by conventional diffusion bonding methods, for which the interfacial chemistry and other factors may differ. ${ }^{12-19}$

\section{Background}

The driving force for fracture at a bimaterial interface is commonly described in terms of the complex stress-intensity factor, $\underline{K}$, first introduced by Rice and $\mathrm{Sih}^{20,21}$ and further developed by Rice: $^{22}$

$$
\underline{K}=K_{1}+i K_{2}=g(\alpha, \beta)\left(K_{I}^{\infty}+i K_{I I}^{\infty}\right) L^{-i \varepsilon} e^{i \omega(\alpha, \beta, L)},
$$


where $K_{I}^{\infty}$ and $K_{I I}^{\infty}$ are the far-field applied mode I and II stress intensities that apply for a monolithic sample of the same dimensions. The elastic mismatch across the interface is described by $\alpha$ and $\beta$, the non-dimensional Dundurs' parameters given by: ${ }^{23}$

$$
\begin{gathered}
\alpha=\frac{E_{1}^{\prime}-E_{2}^{\prime}}{E_{1}^{\prime}+E_{2}^{\prime}}, \\
\beta=\frac{1}{2}\left[\frac{\mu_{1}\left(1-2 v_{2}\right)-\mu_{2}\left(1-2 v_{1}\right)}{\mu_{1}\left(1-2 v_{2}\right)+\mu_{2}\left(1-2 v_{1}\right)}\right],
\end{gathered}
$$

where $E_{1}^{\prime}$ and $E_{2}^{\prime}$ are Young's moduli ( $E$ in plane stress, $E /\left(1-v^{2}\right)$ in plane strain), $v_{1}$ and $v_{2}$ are Poisson's ratios, and $\mu_{1}$ and $\mu_{2}$ are the shear moduli for materials 1 and 2 , respectively. The length parameter $L$ is often defined as the shortest in-plane length parameter for the given geometry, while $\varepsilon$ is a function of elastic mismatch given by:

$$
\varepsilon=\frac{1}{2 \pi} \ln \left(\frac{1-\beta}{1+\beta}\right)
$$

The functions $g(\alpha, \beta)$ and $\omega(\alpha, \beta, L)$ are geometry specific, with $\omega(\alpha, \beta, L)$ thought of as a phase shift that rotates the stress field at a distance $L$ from the crack-tip, relative to that expected from farfield loading.

While complex stress-intensity solutions for interface cracks in sandwich specimens (thin layer bonded between two like members) exist, ${ }^{24}$ it should be noted that different solutions are required for cracks that deviate off the interface, ${ }^{25}$ complicating analysis for cracks that may not lie entirely at the interface. Additionally, these stress-intensity solutions are often only valid over distances ahead of the crack tip that are too small for practical use. ${ }^{26}$ Such complications can be avoided in mode I loaded sandwich geometries by using the strain energy release rate, $G$, to evaluate crack driving forces. In particular, it is noted that for sandwich specimens, where the layer thickness, $h$, is small compared to all other relevant sample dimensions, the strain energy release rate is essentially unaffected by the presence of the layer. ${ }^{24} G$ can thus be calculated for mode I loading from standard stress-intensity solutions for monolithic samples, $K_{I}^{\infty}$, using the linear-elastic relationship:

$$
G=\frac{K_{I}^{\infty^{2}}}{E_{1}^{\prime}},
$$


where $E_{1}^{\prime}$ is for the outer material. Note that as a characterizing parameter for interface fracture, $G$ offers the advantages of being easy to compute and invariant with respect to crack position (i.e., at versus near the interface).

The strain energy release rate necessary to cause interface failure, $G_{c}$, however, can be strongly affected by the mode-mixity at the crack tip, which is affected by the elastic mismatch of the two materials. Mode-mixity can be described by the phase angle, $\psi$, which is defined as the arc tangent of the ratio of shear to normal stresses at some distance, $l$, ahead of the crack tip. Defining $\sigma_{12}$ and $\sigma_{11}$ as the shear and normal stresses, respectively, $\psi$ can be written as:

$$
\psi=\tan ^{-1}\left[\left(\frac{\sigma_{12}}{\sigma_{11}}\right)_{l}\right]=\tan ^{-1}\left[\frac{\operatorname{Im}\left(K l^{i \varepsilon}\right)}{\operatorname{Re}\left(K l^{i \varepsilon}\right)}\right] .
$$

While it is a simple matter to transform from one choice of $l$ to another, ${ }^{22,27}$ the dependencies of $\psi$ on the actual distance from the crack tip (as $\varepsilon \ln (l / L)$ ) and possibly on other in-plane length parameters (e.g., crack length) present serious problems in interpreting fracture data. However, for thin layer sandwich samples with predominantly mode I far-field loading (e.g., as with compact-tension specimens), it has been shown that the actual linear elastic phase angle is small at macroscopic values of $l,{ }^{24}$ and that $\psi$ changes very little when $l$ is within the plastic zone of the deformable metal, ${ }^{28}$ implying that this geometry is essentially a mode I specimen. ${ }^{24}$ Thus, because $G_{c}$ is often only weakly sensitive to $\psi$ when it is small, ${ }^{27}$ the strain energy release rate for such mode I configurations can be used to satisfactorily describe the linear elastic driving force for crack advance.

Changes in mode-mixity due to the modulus mismatch, however, can strongly affect crack paths even for small phase angles. Linear elastic analyses of cracks near interfaces in mode I loaded sandwich specimens have enabled the prediction of crack paths as a function of $\alpha$ and $\beta$ based on a crack trajectory determined by the direction for which the mode II stress intensity is zero $\left(K_{I I}=0\right){ }^{29}$ Defining the outer members as material 1 and the layer as material 2 , for $\beta<0$ the crack is expected, based on driving force, to kink towards material 1 and away from the layer independent of the value of $\alpha$. For positive $\beta$, in all cases the direction of high driving force is for the crack to kink towards/into the layer; however, the preferred path within the layer depends on the value of $\alpha$, with both centerline and off-center crack paths possible. Of course, a crack at the 
interface can remain there or deflect into either adjoining material, with the more probable path being that with the highest ratio of driving force $G$ normalized by the intrinsic crack propagation resistance $\Gamma$ along that particular path $(G / \Gamma)$, where the intrinsic resistance reflects the local value of $\psi$.

\section{Experimental Procedures}

\section{(1) Materials and processing}

Details of the materials and PTLP bonding process used to make the alumina/metal/alumina joints for this study are presented elsewhere, ${ }^{5,69}$ so only a brief summary is provided here. The alumina (AD995, Coors Technical Ceramics Co., Oak Ridge, TN) was 99.5\% pure, $\geq 98 \%$ dense, and had a microstructure shown in Fig. 1, with a mean linear intercept of $12 \mu \mathrm{m}$ corresponding to a nominal grain size of $18 \mu \mathrm{m}$ using ASTM standard E112. One $19.5 \mathrm{~mm}$ by $22.5 \mathrm{~mm}$ surface of each $\sim 8.6 \mathrm{~cm}^{3}$ alumina block was ground flat and polished on a lapping machine using progressively finer diamond compounds followed by colloidal silica as a final polishing agent. For each joint, two such alumina blocks were ultrasonically cleaned in various solutions (detergent and water, distilled water, acetone, and isopropyl alcohol) followed by a $1 \mathrm{hr}$ anneal in air at $1000^{\circ} \mathrm{C}$. Copper wire (Consolidated Companies Wire and Associated, Chicago, IL) was cleaned in isopropyl alcohol, bright dipped (5:1 nitric acid:distilled water), rinsed, dried, and evaporated onto the alumina blocks under high vacuum, yielding a $3 \mu \mathrm{m}$ thick coating. A $125 \mu \mathrm{m}$ thick (99.99\% pure) niobium foil (Goodfellow Corp., Malvern, PA) was also cleaned using various solutions (detergent and water, isopropyl alcohol, ethanol, and nanopure water). After drying, the cleaned niobium foil (also $19.5 \mathrm{~mm}$ by $22.5 \mathrm{~mm}$ ) was sandwiched between the polished surfaces of two copper-coated alumina blocks. The assembly was then loaded into a graphite hot press and processed at $1390-1400^{\circ} \mathrm{C}$ for $6 \mathrm{hr}$. Heating was executed at $4^{\circ} \mathrm{C} / \mathrm{min}$, while cooling was at $2^{\circ} \mathrm{C} / \mathrm{min}$. A 2.2 MPa load was maintained for the entire heating, soaking, and cooling cycles of the process. Five compact-tension, $\mathrm{C}(\mathrm{T})$, fracture and fatigue specimens were machined from each joint as well as from blocks of the as-received alumina.

The bonding process described above resulted in a multi-phase interlayer microstructure with the majority of the bonded interfacial area consisting of alumina bonded directly to niobium, while roughly $11 \%$ of the interfacial area contained isolated regions of copper located between the 
niobium and alumina. Additionally, some residual interfacial porosity was present, on the order of a few percent, which appeared to comprise a greater area fraction near the edges of the bonded blocks. As seen in Table I, the coefficients of thermal expansion (CTE's) of alumina and niobium are similar; therefore, residual stresses due to thermal expansion mismatch between those materials are expected to be small. Conversely, since copper has a CTE more than double that of both niobium and alumina, the regions of copper at the interface are expected to be in a triaxial state of residual tensile stress. Some mechanical properties for the materials used in this study are listed in Table I, while the calculated values of $\alpha$ and $\beta$ for this system are tabulated in Table II. The most relevant of these mismatch parameters are for the mismatch between the alumina and the niobium layer since these two materials make up the majority of the joint interface.

\section{(2) Fracture experiments}

Interfacial fracture toughness experiments were carried out on $3 \mathrm{~mm}$ thick, $17 \mathrm{~mm}$ wide fatigue pre-cracked $\mathrm{C}(\mathrm{T})$ specimens, tested in room air at $25^{\circ} \mathrm{C}$ and $20-40 \%$ relative humidity. Additionally, elevated temperature fracture experiments were conducted at $800^{\circ} \mathrm{C}$ and $1000^{\circ} \mathrm{C}$ in an inert, gettered argon environment. For both ambient and elevated temperature tests, precracking was performed by fatigue cycling at room temperature until cracking initiated at a machined notch $\left(\sim 0.2 \mathrm{~mm}\right.$ wide, with length $\left.a_{\mathrm{o}} \approx 5 \mathrm{~mm}\right)$ in the alumina, adjacent to the bonded layer. With continued cycling, cracks were drawn to the interface by modulus mismatch effects, at which point crack propagation occurred largely along the interface. Prior to monotonically loading to failure, the cyclic loads were incrementally reduced until the fatigue-crack growth rates were on the order of $10^{-10} \mathrm{~m} /$ cycle, thus minimizing the size of the cyclic fatigue-damage zone. Crack-driving forces were assessed using the strain energy release rate, with $G_{\mathrm{c}}$ defined as the critical driving force required for fracture; values were computed from the peak load and crack length at failure using Eq. 4 along with standard stress-intensity solutions for $\mathrm{C}(\mathrm{T})$ specimens. ${ }^{30}$ For comparison, the fracture resistance of monolithic alumina samples was measured as a function of crack extension in the form of a crack resistance curve (R-curve).

\section{(3) Fatigue-crack growth experiments}


Fatigue-crack growth rates were measured in room air at $25^{\circ} \mathrm{C}$ and $20-40 \%$ relative humidity in general accordance with ASTM standard E647 using large $\left(\Delta a_{f}>2 \mathrm{~mm}\right)$, through-thickness cracks in $\mathrm{C}(\mathrm{T})$ specimens, where $\Delta a_{f}$ is the length of the fatigue crack extension as measured from the end of the machined notch. Some specific modifications for the sandwich test geometry are described below, while other details specific to sandwich samples can be found elsewhere. ${ }^{31,32}$ Tests were conducted at a frequency of $25 \mathrm{~Hz}$ (sine wave) using computer-controlled servohydraulic testing machines at a constant load ratio, $R=P_{\min } / P_{\max }$, of 0.1 , where $P_{\max }$ and $P_{\min }$ are, respectively, the maximum and minimum applied loads in the cycle. Crack lengths were continuously monitored with unloading compliance methods using strain gauges mounted on the back face of the specimens, specifically on the alumina surface adjacent to the metal layer. Compliance calibrations for standard monolithic $\mathrm{C}(\mathrm{T})$ specimens $^{33}$ were used and proved to be reasonably accurate based on direct crack length measurements for the present thin layer sandwich specimens. Crack-driving forces were assessed using the range of strain energy release rate, $\Delta G=$ $G_{\max }-G_{\min }$. Data are presented in terms of plots of the fatigue-crack growth rate $(\mathrm{d} a / \mathrm{d} N)$ as a function of the applied driving force $(\Delta G)$, measured under both increasing and decreasing $\Delta G$ conditions. Specifically, cracks were initiated by cycling until stable cracks formed at a machined notch in the alumina next to the bonded layer. These cracks were then propagated until they reached the interface, after which point the loads were either incrementally reduced to measure the behavior approaching the threshold $\left(\Delta G_{\mathrm{TH}}\right.$ being operationally defined as the applied $\Delta G$ corresponding to growth rates below $\sim 10^{-10} \mathrm{~m} /$ cycle), or increased to obtain the high velocity portion of the crack-growth curves. For practical considerations, tests were controlled using the far field applied stress-intensity range, $\Delta K_{I}^{\infty}$, with continuous load shedding that limited the $\Delta K_{I}^{\infty}$ gradient $\left(=1 / \Delta K_{I}^{\infty}\left[\mathrm{d} \Delta K_{I}^{\infty} / \mathrm{d} a\right]\right)$ to $\pm 0.08 \mathrm{~mm}^{-1}$. Ideally, this rate of change in loads would be sufficiently slow to allow the crack blunting or bridging levels to adjust to the current load and level of $\Delta K_{I}^{\infty}$ or $\Delta G$, i.e., the crack extension at each load level exceeds several plastic-zone sizes. Additionally for comparison, similar fatigue-crack growth experiments were carried out on bulk alumina samples with both long $\left(\Delta a_{f}>2 \mathrm{~mm}\right)$ and short $\left(\Delta a_{f}<2 \mathrm{~mm}\right)$ crack sizes.

\section{(4) Interface analysis}


Fracture surfaces were evaluated using a scanning electron microscope (SEM) equipped with an energy dispersive spectral analyzer for elemental analysis (EDS) and interfacial chemistry was assessed using Auger electron spectroscopy (AES). Fractured surfaces were analyzed in a scanning Auger spectrometer (SAM 660, Perkin Elmer) after notched bars (3 $33 \mathrm{~mm}^{2}$ cross section) were fractured in situ in the spectrometer chamber. Indentation cracks were introduced on the sample sides ahead of the notch to direct the cracks towards the desired interface. If only a fraction of a monolayer (ML) of segregant, A, is located at the analyzed surface, the fractional coverage, $\Theta_{A}$, can be calculated as: ${ }^{34-36}$

$$
\frac{I_{A}}{I_{B}}=\frac{I_{A}^{\infty}}{I_{B}^{\infty}} \cdot \frac{\Theta_{A} \cdot\left[\frac{1+r_{B}\left(\xi_{A}\right)}{1+r_{A}\left(\xi_{A}\right)}\right]\left(1-\exp \left[-\frac{d_{A}}{\lambda_{A}\left(\xi_{A}\right) \overline{\cos \varphi}}\right]\right)}{1-\Theta_{A}+\Theta_{A} \cdot \exp \left[-\frac{d_{A}}{\lambda_{A}\left(\xi_{B} \overline{\cos \varphi}\right.}\right]} .
$$

Here $I_{A} / I_{B}$ is the intensity ratio for the segregant $\mathrm{A}$ and substrate element $\mathrm{B}$ at energies $\xi_{A}$ and $\xi_{B}$, respectively and $d_{A}$ is the atomic diameter of the segregant. The mean free path $\lambda_{i}(\xi)$ of Auger electrons of energy $\xi$, and the back scattering coefficients $r_{i}(\xi)$ depend on composition and were estimated as in refs. 34-36. The angle $\varphi$ is that between the normal of the object surface and the detector axis. Standard intensities $I_{i}^{\infty}$ of the pure elements were measured under the same conditions. In the presence of two impurity elements, A1 and A2, the percent coverage for each was determined similarly.

\section{Results}

\section{(1) Fracture toughness results}

At room temperature, the PTLP bonded $\mathrm{C}(\mathrm{T})$ samples were found to fracture at the niobium/alumina interface at a mean driving force of $39 \mathrm{~J} / \mathrm{m}^{2}$. The interfacial fracture toughness decreases with increasing temperature up to $1000^{\circ} \mathrm{C}$, as shown in Fig. 2. The mean fracture energy decreases by almost $50 \%$ from $39 \mathrm{~J} / \mathrm{m}^{2}$ at room temperature to $21 \mathrm{~J} / \mathrm{m}^{2}$ at $1000^{\circ} \mathrm{C}$. The 
load-deflection curves were essentially linear to failure and there was no evidence of increasing fracture resistance with increasing crack length under monotonic loading.

Due to alumina grain pullout during prior fatigue testing, pre-cracks typically did not lie entirely at the interface, with a portion of the crack front being located in the alumina near the interface. With monotonic loading, however, the crack was quickly drawn to the interface and propagated primarily along it with almost no alumina grain pullout. Observations of the fracture surfaces indicate that the niobium debonded from the alumina in a brittle manner leaving no visible deformation markings (up to magnifications of 50,000X); instead, undistorted imprints of the alumina grain boundaries are visible on the niobium regions of the fracture surface (Fig. 3a). Additionally, small regions rich in both niobium and silicon, identified as $\mathrm{Nb}_{5} \mathrm{Si}_{3}$ by EDS, were observed on the alumina sides of the fracture surfaces and ranged from $\sim 40$ to $1 \mu \mathrm{m}$ in diameter. These regions account for only a small percentage of the fracture area and appeared to fracture in a brittle manner. The majority were only a few micrometers in size located at alumina grain boundaries and triple points (Fig. 3), while the largest $\mathrm{Nb}_{5} \mathrm{Si}_{3}$ regions were located over patches of small alumina grains (Fig. 4). In contrast, regions of interfacial copper, typically several micrometers in size and also identified by EDS, deformed plastically and adhered to both sides of the fracture surface (Fig. 3).

\section{(2) Fatigue-crack growth results}

Under fatigue loading, cracks propagated at or near the niobium/alumina interface with various amounts of alumina grain pullout (i.e., shallow excursions of the crack into the alumina). Resulting fatigue-crack growth rates, $\mathrm{d} a / \mathrm{d} N$, at room temperature are shown in Fig. 5 and are compared with corresponding data collected for large $\left(\Delta a_{f}>2 \mathrm{~mm}\right)$ fatigue cracks propagating in bulk alumina samples. The fatigue-crack growth rate behavior can be expressed in terms of a standard fatigue (Paris) power law:

$$
\mathrm{d} a / \mathrm{d} N \propto \Delta G^{m},
$$

with the power-law exponents, $m$, ranging from 10 to 50 for the four samples shown. These exponents are far larger than those commonly measured in metallic alloys but are similar to those found for the cyclic fatigue of brittle materials $;{ }^{37}$ for example, the results measured in the present investigation for bulk alumina display a power-law exponent of $\sim 50$. 
With respect to the crack path, the amount of ceramic grain pullout during fatigue-crack growth varied quite widely, with alumina grains covering from $\sim 50$ to nearly $100 \%$ of the niobium side of the fracture surface. Representative micrographs for each case are shown in Fig. 6. For the latter case, cracks propagated mostly intergranularly in the alumina; however, they were constantly drawn back to the interface, resulting in a near-interfacial crack path. Interface samples in which the fatigue crack propagated primarily in the alumina exhibited growth rates and powerlaw exponents comparable to that of monolithic Coors AD995 alumina (Fig. 5).

Samples with less alumina grain pullout had appreciable portions of the crack front propagating at the niobium/alumina interface and demonstrated less fatigue-crack growth resistance. Indeed, samples with $\sim 100 \%$ coverage of alumina grains on the fatigue fracture surface exhibited fatigue-crack growth thresholds $\sim 50 \%$ higher when compared with samples having only $\sim 50 \%$ coverage. Fracture surfaces in regions where the fatigue crack grew at the interface (Fig. 7) looked similar to those of fast fracture (Fig. 3); the only notable difference was

in the morphology of the copper regions. Copper regions at the interface adhered to both sides of the fatigue fracture surface and appeared deformed; however, in the case of fatigue, these regions were flattened due to crack closure during the cyclic loading while also exhibiting evidence of partial copper/alumina interface failure in some places (Fig. 7). Scanning electron microscopy revealed no visible deformation or fatigue markings (e.g., fatigue striations or beachmarks) on the niobium portions of the fatigue fracture surface up to magnifications of $\sim 50,000 \mathrm{X}$. Indeed, as in fast fracture, imprints of the alumina grain boundaries were still clearly visible on the niobium after fatigue failure, implying a relatively brittle debonding mechanism had operated in these regions (Fig. 7).

\section{(3) Interface chemistry}

The results of AES analysis of fracture surfaces of both the $\mathrm{Nb}$ and alumina sides are summarized in Table III for regions where the $\mathrm{Nb}$ had been directly in contact with alumina (based upon grain boundary groove imprints, as in Fig. 3). Survey spectral scans from several areas on the $\mathrm{Nb}$ side, each having been bonded to a different alumina grain, consistently revealed peaks for $\mathrm{Nb}$ plus $\mathrm{Cu}$ and $\mathrm{O}$; smaller peaks that corresponded to Ti were seen only occasionally. Special scans were then used to quantify $\mathrm{Cu}$ and $\mathrm{O}$ levels which varied considerably but averaged $0.7 \mathrm{ML}$ and $0.5 \mathrm{ML}$, respectively. The $\mathrm{Nb}$ surfaces slowly adsorbed $\mathrm{O}$ from the chamber during analysis; 
plots of oxygen coverage versus time after sputter-cleaning using Ga ions (guided by a Monte Carlo model for attachment) were used to correct the oxygen coverages to levels expected immediately after fracture. The alumina fracture surface experienced some charging which frustrates quantitative analysis; however, areas that had been directly bonded to the $\mathrm{Nb}$ showed the expected $\mathrm{Al}$ and $\mathrm{O}$ peaks, and often very small peaks corresponding to the main $\mathrm{Nb}$ peaks at low energy (nominally at 167 and $197 \mathrm{eV}$ ). No Cu was evident at such regions. Both $\mathrm{Ca}$ and $\mathrm{Si}$ was detected easily on intergranular regions of the fractured alumina, with the grain boundaries containing $\mathrm{Ca}$ segregant and Si being largely confined to glassy pockets. Neither element was detectable on either side of the fractured niobium/alumina interface in the regions where there was direct $\mathrm{Nb}$ /alumina contact, i.e., away from the alumina grain boundary groove imprints. Thus, the directly bonded $\mathrm{Nb} / \mathrm{Al}_{2} \mathrm{O}_{3}$ interfacial regions are free of the glassy silicate material that is present in the alumina, but have segregated $\mathrm{Cu}$ at submonolayer levels, which presumably was in local equilibrium with the isolated pockets of molten copper during bonding.

\section{Discussion}

Measured room temperature fracture toughness values of $39 \mathrm{~J} / \mathrm{m}^{2}$ for the present joints fall in the middle of the range reported for diffusion bonded polycrystalline alumina/niobium samples under mode I loading $\left(9-90 \mathrm{~J} / \mathrm{m}^{2}\right),{ }^{12-15,18,19}$ demonstrating that comparable toughness values can be obtained by utilizing a PTLP bonding process that offers the convenience of potentially lower bonding temperature and/or pressures and less rigorous polishing requirements for the bonding surface. This level, however, is well below the range of $70-2400 \mathrm{~J} / \mathrm{m}^{2}$ that has been exhibited by ultra-high vacuum (UHV) diffusion-bonded bicrystals of sapphire/niobium processed with various orientation relations. ${ }^{15-19}$ Such differences can be understood by considering the interfacial chemistry and specific mechanisms of toughening in the present PTLP bonded case. While interfacial porosity and brittle fracture/pullout of $\mathrm{Nb}_{5} \mathrm{Si}_{3}$ particles are considered to have minor contributions to the measured crack resistance, ductile tearing of copper particles and frictional grain bridging in the alumina are expected to contribute significantly to the measured fracture resistance, and will be the focus of further discussion. The results are analyzed first in terms of factors that the control the crack paths observed under various loading conditions and then considering the crack extension mechanisms and determinants of fracture resistance. 


\section{(1) Crack trajectories}

During fracture testing, pre-cracks that initially had crack fronts located partially in the alumina were drawn to, and propagated along, the niobium/alumina interface. This crack deflection towards the interface is consistent with the highest driving force direction predicted by Ritchie $e t a l{ }^{29}$ for positive $\beta$ values. While some highly localized crack deflections into the metallic layer occurred, in general under monotonic loading cracks were not observed to deviate into the layer and follow the path of largest driving force. To explain this, the relative toughness of the layer and the interface must additionally be considered. The occurrence of crack propagation along the interface indicates that the toughness of the niobium layer must exceed that of the interface, i.e., $\Gamma_{\mathrm{Nb}}>\Gamma_{\mathrm{i}}$, thus preventing further crack deflection into the metal layer and, thereby, trapping the crack at the interface. Moreover, it can also be inferred from the predominance of an interfacial crack path that the interface toughness must be less than, or approximately equal to, the alumina toughness, $\Gamma_{\mathrm{i}} \leq \Gamma_{\mathrm{a}}{ }^{29}$ If instead the toughness of the interface were appreciably higher than that of the alumina, episodic kinking into the alumina could be expected, as has been observed with bonds of $\mathrm{Al} / \mathrm{Al}_{2} \mathrm{O}_{3} \cdot{ }^{32,38}$

The occasional small, local crack deflections into the metal interlayer that did occur, under both monotonic and cyclic loading, left regions identified as $\mathrm{Nb}_{5} \mathrm{Si}_{3}$ on the alumina side of the fracture. Such crack kinking appears to occur where the niobium contacts the alumina grain boundaries and can interact with the intergranular glassy phase, suggesting that such regions are a result of local reaction of the niobium with intergranular silica to form $\mathrm{Nb}_{5} \mathrm{Si}_{3}$, which is known to be brittle $\left(K_{\mathrm{IC}} \approx 3 \mathrm{MPa} \sqrt{ } \mathrm{m}^{39}\right)$. While local embrittlement of niobium in the presence of silicon has been previously observed to affect fracture paths in both PTLP bonds ${ }^{40}$ and diffusion bonded ${ }^{41}$ alumina/niobium joints, the specific silicide $\mathrm{Nb}_{5} \mathrm{Si}_{3}$ was not identified in those investigations.

Under cyclic loading, cracks repeatedly grew into the alumina but were constantly drawn back to the interface, resulting in regions of near-interfacial crack path. While crack deflection toward the interface is in agreement with driving force considerations based on monotonic loading, ${ }^{29}$ crack deflection back into the alumina suggests that the relative resistance to crack growth is again important for cyclic loading. Thus, it can be inferred that the niobium/alumina interface must have a higher intrinsic resistance to fatigue-crack propagation compared to that of the alumina in regions where near-interfacial (alumina) crack propagation is prevalent, i.e., $\Gamma_{\mathrm{i}}^{\mathrm{cyc}} \geq \Gamma_{\mathrm{a}}^{\mathrm{cyc}}$. While the modulus mismatch effects draw the crack to the interface, the lower intrinsic fatigue-crack 
propagation resistance of some alumina grain boundaries evidently allows the crack to deviate again back into the ceramic. This may be expedited by the deflections initiating at pre-existent flaws in the alumina.

\section{(2) Fracture behavior and toughening mechanisms}

Under monotonic loading at both ambient and elevated temperatures, observations indicate that fracture occurred by brittle separation of the niobium/alumina interface accompanied by ductile tearing of the copper regions. No deformation marks were observed on the niobium side of the fracture surface; this is in contrast to observations made on UHV bonded bicrystals, which showed distinct slip steps and blunting steps on the fracture surfaces as a result of plastic deformation. ${ }^{18,19,42}$ While the strain rate sensitivity of niobium is expected to play a role in reducing deformation during fast fracture, no evidence of deformation was found at the critical fracture initiation point where the loading rate was moderate and more deformation should be expected.

In contrast to niobium, as the interface crack encountered a copper region during fracture, the copper deformed plastically, absorbing energy, which in turn contributed to the measured fracture energy. This toughening mechanism is analogous to that seen in ductile-phase reinforced composites, where distributed ductile phases are used to increase the toughness of brittle materials. ${ }^{43-46}$ Indeed, deformed copper regions on the fracture surfaces in the present study look identical in morphology to deformed aluminum on the fracture surface of an aluminum-reinforced alumina composite. ${ }^{44}$

A rough estimate of the toughening contribution from the ductile copper phase can be made by using an expression developed for ductile-phase reinforced brittle composites: ${ }^{44,47,48}$

$$
\delta G_{c}=V_{f} \sigma_{o} t \chi,
$$

where $V_{f}$ is the volume fraction, $\sigma_{o}$ the yield strength, and $t$ the particle radius of the reinforcing phase; $\chi$ is a work of rupture parameter. In the present case, $\chi$ is expected to be approximately unity for a fully ductile ligament independent of temperature. ${ }^{44}$ Estimating the room temperature yield strength for fully annealed copper as $100 \mathrm{MPa}$ and using a measured average copper particle radius of $2 \mu \mathrm{m}$, we predict a toughening contribution of $22 \mathrm{~J} / \mathrm{m}^{2}$, or $\sim 60 \%$ of the room temperature fracture energy. As the temperature is increased towards the melting point of the 
copper $\left(T_{\mathrm{mp}}=1083^{\circ} \mathrm{C}\right)$, the yield strength of copper is expected to decrease, thereby lowering this toughening contribution. Indeed, the $18 \mathrm{~J} / \mathrm{m}^{2}$ drop in fracture energy that was observed for fracture at $1000^{\circ} \mathrm{C}$ is consistant with the loss of most of this predicted toughening contribution; however, lacking further evidence it is unclear whether this is indeed the primary factor causing the decrease in toughness with increasing temperature.

As mentioned previously, fatigue pre-cracks used for fracture testing were located in part in the near-interfacial alumina. When intergranular fracture is predominant in bulk alumina, frictional tractions that develop along the fractured grain boundaries in the crack wake are known to sustain load during monotonic loading, thereby shielding the crack tip from a portion of the applied driving force and resulting in rising toughness with crack extension. ${ }^{49-51}$ The result of such behavior is illustrated in Fig. 8 in the form of a rising R-curve for this Coors AD995 alumina. Indeed, such an effect may have contributed to the presently measured interfacial toughnesses; if so, variations in the specific pre-crack morphology may account for some of the scatter in the fracture toughness data where differences in the proportion of interfacial versus alumina crack wake for individual samples may have led to different contributions of grain bridging.

Considering such factors, the actual $\mathrm{Nb} / \mathrm{Al}_{2} \mathrm{O}_{3}$ interface toughness may be $\leq 20 \mathrm{~J} / \mathrm{m}^{2}$, which is lower than for most diffusion bonded $\mathrm{Nb} / \mathrm{Al}_{2} \mathrm{O}_{3}$ interfaces. Generally, those toughness values depend on bonding temperature in two opposing ways. Using higher temperature beneficially eliminates interfacial porosity but also increases oxygen contamination of the $\mathrm{Nb}$, thereby, raising the yield stress. Thus, diffusion bonding at $1300-1400^{\circ} \mathrm{C}$, accomplished with very flat and clean bonding surfaces under UHV conditions, has yielded interfaces with fracture energies of $90 \mathrm{~J} / \mathrm{m}^{2}$ using $99.9 \%$ pure $\mathrm{Nb} .{ }^{18,19}$ Possible explanations for the lower toughness in the present case may be a much higher yield strength for the present polycrystalline niobium due to impurity uptake during bonding and/or a decrease in the work of attraction, $W_{a t}$, due to copper adsorbed at the interface allowing interface failure at lower toughness values.

Such effects on toughness can be appreciated by noting that the toughness of a ceramic/metal interfacial crack under conditions of plane strain and small-scale yielding (SSY) relative to the entire sample can be conceived as: ${ }^{52,53}$

$$
G_{c}=\xi W_{a t}+f\left(\xi W_{a t} / \sigma_{o} b, E^{*} / \sigma_{o}, h / r_{y}^{\infty}, \psi\right)
$$


where $b$ is an atom spacing, and $E^{*}$ the effective elastic modulus $\left(2 / E^{*}=1 / E_{1}^{\prime}+1 / E_{2}^{\prime}\right)$. The work of attraction for the interface, $W_{a t}$, corresponds to the work of adhesion under fracture conditions in which any interfacial impurity is partitioned between the two newly formed interfaces; $\xi W_{a t}$ describes the atomic bond rupture resistance of the interfacial crack absent any plasticity, but for which dissipation owing to atom trapping is accounted by the term $\xi$ which may be of order $1-5 .{ }^{54}$ The nominal extent of the plane-strain plastic zone into a thick deformable metal normal to a bimaterial interface, $r_{y}^{\infty}$, is expected to be similar to that of the homogeneous case, ${ }^{55,56}$ and may be approximated by $r_{y}^{\infty} \approx G_{c} E^{*} / 2 \pi \sigma_{o}{ }^{2}$. While Eq. 9 reveals that having lower $\sigma_{o}$ in general raises toughness due to increased crack blunting and plastic dissipation, if a deformable interlayer between elastic members has a layer thickness, $h$, that is thinner than $r_{y}^{\infty}$, the plasticity contribution to the toughness may be limited by constraint of the plasticity. ${ }^{38}$

Vickers microhardness $\left(\mathrm{H}_{\mathrm{V}}\right)$ measurements were made on the $\mathrm{Nb}$ interlayer using a $100 \mathrm{~g}$ load to provide an estimate of the yield stress for the PTLP bonded material. On a fine polished surface on the side of a sample, $\mathrm{H}_{\mathrm{V}}=1.7 \mathrm{GPa}$ was found, while a hardness of $2.4 \mathrm{GPa}$ was found on the fracture surface. Both values could be high owing to polishing damage or crack-tip plasticity, respectively. To assess this, a sandwich sample was produced by the standard bonding heat treatment, but specially prepared by using a low load and omitting the $\mathrm{Cu}$ at one of the interfaces to allow easy interfacial separation. After breaking off the poorly bonded alumina, the hardness measured on the $\mathrm{Nb}$ surface formerly in contact with the alumina was $H_{\mathrm{V}}=2.6 \mathrm{GPa}$; additional measurements on a portion of the niobium surface that was not in contact with the alumina during bonding gave $H_{\mathrm{V}}=2.4 \mathrm{GPa}$. All these values are markedly higher than found after UHV diffusion bonding using cleaner $\mathrm{Nb}$ single crystals at $1400^{\circ} \mathrm{C} .^{18,19}$ Using the classical relation $\sigma_{o} \approx H_{\mathrm{V}} / 3$ gives a yield stress exceeding $550 \mathrm{MPa}$, which combined with an interfacial toughness of $20 \mathrm{~J} / \mathrm{m}^{2}$ implies a very small plastic-zone height, $r_{y}^{\infty} \approx 3 \mu \mathrm{m}$, into the niobium, which is far less than the layer thickness. While prior experience has shown that for coarse grained or single crystal niobium the estimate of $H_{\mathrm{V}} / 3$ can lead to an overestimation of the yield stress and an underestimation of the plastic-zone size, ${ }^{18,19}$ this hardness exceeds that expected for other diffusion bonded samples and the high yield stress may be one cause of the low interfacial toughness found here.

Regarding the $W_{a t}$, the segregated copper may play a similar role to that for silver, which has been reported to strongly decrease the toughness of UHV bonded niobium/sapphire bicrystals. It 
was found that submonolayer silver doping lowered the work of attraction, thereby decreasing the ability for cracks to blunt or deform the $\mathrm{Nb}$ by allowing easier interfacial separation; the toughness decreased monotonically with $W_{a t}{ }^{16-19}$ For fracture energies below $100 \mathrm{~J} / \mathrm{m}^{2}$, the behavior was interpreted as involving interfacial cracks that are virtually sharp as compared to those for samples with higher $W_{a t}$, where a blunting transition occurs leading to much greater toughnesses ${ }^{\S}{ }^{18,19}$ Thus, with the high yield stress implied, and some prospect of the copper adsorption having degraded the chemical bonding at the interfaces, it is likely that the interfaces for the present samples fail in a quasi-brittle, virtually sharp-crack regime.

\section{(3) Mechanisms of cyclic fatigue crack advance}

Interfacial cyclic fatigue-crack growth also appeared to occur by relatively brittle separation of the niobium/alumina interface with accompanying ductile separation of the copper regions, but with a greater tendency toward crack deflection into the alumina. No fatigue or deformation markings of any kind were observed on the fatigue surface of niobium, which is in contrast to results on the fatigue of alumina/aluminum, where interfacial fracture is promoted by cyclic loading and ductile fatigue striation markings were observed on the metal side of the interfacial fatigue surface. ${ }^{32,38}$ Possible explanations for this difference may again involve such factors as the higher yield strength for the present niobium relative to aluminum and/or a lower $W_{a t}$ allowing brittle interface separation with minimal blunting.

Evidence of deformed copper adhering to both sides of the fatigue surface does suggest, however, that a ductile fatigue mechanism operates in these regions. Again this appears to be analogous to a ductile-phase reinforced brittle-matrix composite, where resistance to fatigue-crack propagation arises from the fatigue resistance of the ductile reinforcing phase. ${ }^{46,59}$ Although ductile-phase reinforcement has proven to be less effective under cyclic loading as compared to monotonic loading, it has been demonstrated that fatigue-crack growth resistance can be imparted

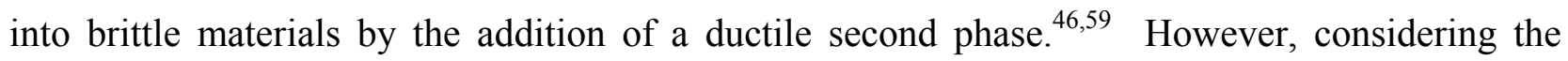
behavior for $\mathrm{Al} / \mathrm{Al}_{2} \mathrm{O}_{3}$ interfaces, for which cycling usually leads to complete interfacial separation, it may be surprising that inspection of the present fracture surfaces reveals only a limited amount of direct separation of the $\mathrm{Cu} / \mathrm{Al}_{2} \mathrm{O}_{3}$ interface and instead predominantly ductile

\footnotetext{
$\S$ This interpretation is plausible, although there are outstanding mechanics questions as to how the near-crack tip deformation occurs without causing discernable blunting, ${ }^{52}$ specifically whether dislocation cell structures can account for this ${ }^{57}$ and whether strain-gradient effects can describe it. $^{58}$
} 
failure in the $\mathrm{Cu}$ bridges (Fig. 7). Evidently, the $\mathrm{Nb} / \mathrm{Al}_{2} \mathrm{O}_{3}$ interface crack proceeds ahead of the $\mathrm{Cu}$ particles, leaving less constrained bridges that fail in fatigue.

As mentioned previously, near-interfacial fatigue-crack propagation frequently occurs in the alumina. Investigations into the cyclic fatigue-crack growth properties of bulk Coors AD995 alumina have demonstrated a true cyclic fatigue effect operates, with degradation in grain bridging attributed as the mechanism associated with the cyclic-induced propagation of the crack. ${ }^{60}$ The tendency for easy grain boundary fracture in this material leads to tortuous crack paths resulting in grain bridging in the crack wake that provides macroscopic toughening. Ca segregation found by AES at these alumina grain boundaries may lower the grain boundary toughness, causing the grain boundary fracture that results in such bridging effects, as was also found by Cook and Schrott. ${ }^{61}$ Then as a crack is cycled open and closed, the grain bridges degrade by such processes as frictional wear, allowing for crack advance at lower applied driving forces, ${ }^{60,62-65}$ a process that most likely applies in the present samples as well.

The sample-to-sample variation in the measured fatigue-crack growth rates correlates directly with the variation in the proportion of interfacial versus near-interfacial (alumina) crack path (Fig. 5). As argued previously, based on linear elastic crack-path predictions, ${ }^{29}$ the intrinsic fatiguecrack growth resistance at the alumina grain boundaries is expected to range locally from being comparable to slightly lower than that of the $\mathrm{Nb} / \mathrm{Al}_{2} \mathrm{O}_{3}$ interface (i.e., $\Gamma_{\mathrm{i}}{ }^{\text {cyc }} \geq \Gamma_{\mathrm{a}}{ }^{\text {cyc }}$ ) to allow both crack-propagation paths to be active. Thus, in order to explain the higher global crack-growth resistance that is measured when predominantly near-interfacial (alumina) fatigue-crack growth occurs (Fig. 5), extrinsic toughening mechanisms in the alumina (i.e., grain bridging) must be taken into account. Specifically, samples with only $\sim 50 \%$ of the crack wake being in the alumina experience less grain bridging and correspondingly higher near-tip driving forces, leading to lower measured fatigue-crack growth resistances, compared to samples with closer to $100 \%$ alumina crack path.

Supporting evidence for this notion is adduced by considering the case of short-crack ${ }^{\ddagger}$ fatigue effects in bulk alumina. With such short cracks, the extent of bridging in the crack wake is also limited; however, in this case the effect is due to the restricted size of the crack wake rather than the crack-wake morphology. Evidence from recent studies indicates that the grain-bridging zone

\footnotetext{
\$ Short or small fatigue cracks are defined as cracks small compared to: (i) the scale of microstructure, (ii) the extent of local inelasticity, or (iii) the extent of crack-tip shielding in the crack wake, where short cracks are small in one dimension and small cracks are small in all dimensions. They can generally grow at rates in excess of corresponding large cracks due to a higher local (near-tip) driving force experienced at the crack tip. ${ }^{6}$
} 
in the crack wake does not become fully developed and reach a steady-state in Coors AD995 alumina until the fatigue-crack length, $\Delta a_{f}$, exceeds approximately $2 \mathrm{~mm}$, which corresponds to a distance behind the crack tip where the estimated crack opening is $\sim 1 / 16$ of the average grain size. $^{38}$ Fig. 9 shows fatigue-crack growth data from short cracks $\left(\Delta a_{f}<2 \mathrm{~mm}\right)$ compared to data from long cracks $\left(\Delta a_{f}>2 \mathrm{~mm}\right)$ in AD995 alumina, demonstrating a marked decrease in fatigue resistance for the short cracks due to reduced grain bridging. Although the intrinsic (crack-tip) resistance to crack growth in the alumina is considered to be the same for both long and short cracks, the measured crack-growth resistance is higher for the long cracks due to a fully developed grain-bridging zone that is able to support more of the load. It is noted that if one considers shortcrack fatigue behavior as a lower-bound and long-crack fatigue behavior as an upper-bound on fatigue-crack growth rates, the data shown in Fig. 9 for cracks in bulk alumina span the full range of behavior observed for the fatigue of the PTLP bonded joints tested. This demonstrates that stochastic variations in grain bridging can indeed account for the scatter in the fatigue data for the PTLP bonded joints, consistent with the correspondence of high crack-growth resistance to a high percentage of alumina grain pullout on the fracture surface.

Recognizing this grain bridging scenario allows further elaboration of interfacial fatigue mechanism; it actually entails a process of relatively brittle separation of the niobium/alumina interface accompanied by ductile fatigue of the interfacial copper patches, with the latter being more sensitive to cycling. Taking the lower range of measured resistance values, in which the contribution from bridging in the alumina is minimal, implies that the interfacial resistance is $\Delta G$ $\leq 20 \mathrm{~J} / \mathrm{m}^{2}$ for cyclic extension near threshold conditions. This would correspond with $G_{\max }$ being approximately equal to the expected interfacial toughness deduced previously if there is only limited cyclic degradation actually occurring at the $\mathrm{Nb} / \mathrm{Al}_{2} \mathrm{O}_{3}$ interfacial crack tip, as would comport with the absence of visible striations on the $\mathrm{Nb}$. Then, most of the degradation from cycling compared to the monotonic toughness would seem to involve the reduction (or elimination at threshold) of the bridging forces from the $\mathrm{Cu}$ ligaments.

The implication that the interface is intrinsically tougher than the alumina grain boundaries under cyclic loading (i.e., $\Gamma_{\mathrm{i}}^{\text {cyc }} \geq \Gamma_{\mathrm{a}}^{\text {cyc }}$ ) is surprising given that: i) under monotonic loading, there is little tendency for crack extension into the alumina meaning that the intrinsic toughness of the interface does not exceed that for the alumina grain boundaries (i.e., $\Gamma_{\mathrm{i}} \leq \Gamma_{\mathrm{a}}$ ), and ii) it is widely believed that cyclic loading does not degrade the intrinsic toughness of the brittle ceramic but only 
the extrinsic toughening mechanisms. ${ }^{60,62-65}$ Hence, it is inferred, unexpectedly, that the intrinsic toughness of the $\mathrm{Nb} / \mathrm{Al}_{2} \mathrm{O}_{3}$ interface under subcritical cyclic loading actually exceeds that for rapid fracture under monotonic loading. This is plausible if the cyclic degradation is minimal and given that under monotonic loading of $\mathrm{Nb} / \mathrm{Al}_{2} \mathrm{O}_{3}$ bicrystals, the interfacial fracture toughness was shown to decline markedly as the crack velocity increases. ${ }^{18,19}$ The latter apparently owes to the strain rate sensitivity of the plasticity in the $\mathrm{Nb}{ }^{18,19}$

\section{(4) Reliability of joints}

Comparisons of the mechanical properties of joints to that of the bulk material, in this case alumina, are essential for reliability predictions in joined components. Previous investigations have shown the strength of the PTLP bonded joints to be comparable to that of the alumina used, with the majority of failures occurring in the alumina away from the interface. ${ }^{5,6}$ Fracture toughness tests in the present work have demonstrated a mean interfacial fracture toughness of $39 \mathrm{~J} / \mathrm{m}^{2}$ at room temperature, while the bulk alumina exhibited rising R-curve behavior, with an initiation toughness of $\sim 20 \mathrm{~J} / \mathrm{m}^{2}$ and toughness values increasing to $>40 \mathrm{~J} / \mathrm{m}^{2}$ (i.e., greater than that of the interface) after $\sim 1 \mathrm{~mm}$ of crack extension (Fig. 8). As noted previously, it must additionally be considered that the several millimeter-long fatigue pre-cracks used for the measurement of interfacial fracture toughness were located at least in part in the alumina, and thus alumina grain bridges in the wake of the pre-cracks may have contributed to the measured interfacial fracture toughness. This implies that the measured toughness values (Fig. 2) may only provide an upper-bound to the actual interfacial fracture toughness, and that the interfacial fracture toughness is roughly comparable to that of $<1 \mathrm{~mm}$ long cracks in the bulk alumina. Thus, while bulk alumina has superior fracture toughness in situations where cracks are $>1 \mathrm{~mm}$ in length, the presence of such long cracks in a brittle material is often detrimental and so, in most practical cases, the benefits of higher toughness would not be realized.

In the case of cyclic loading, fatigue-crack growth thresholds for interfacial and nearinterfacial cracking have been found to range from $\sim 20-30 \mathrm{~J} / \mathrm{m}^{2}$, with data for bulk alumina at the upper end of that range $\left(\sim 30 \mathrm{~J} / \mathrm{m}^{2}\right)$. As discussed above, the threshold of $\sim 30 \mathrm{~J} / \mathrm{m}^{2}$ for the bulk alumina can only be achieved after $>2 \mathrm{~mm}$ of crack extension. For shorter cracks, bulk alumina exhibits significantly less fatigue-crack growth resistance, as seen in Fig. 9 in the form of lower fatigue thresholds and faster crack-growth rates at comparable driving forces. This implies 
that the bulk alumina only possesses consistently superior fatigue-crack growth resistance compared to systems containing PTLP joints when cracks are greater than $2 \mathrm{~mm}$ in length, and once again the presence of such long cracks in most cases would be detrimental to the overall mechanical properties of the structure. Thus, based on the results of the present work, considering both monotonic fracture and cyclic fatigue-crack growth, the presence of the PTLP joints does not seem to be detrimental to the overall flaw tolerance of the joined structure for cases when flaws are of reasonably practical sizes $(<1 \mathrm{~mm})$.

\section{Conclusions}

Based on an experimental study of the interfacial and near-interfacial fracture toughness and cyclic fatigue-crack growth properties of partial transient liquid-phase bonded (PTLP) joints consisting of $99.5 \%$ pure alumina bonded with copper/niobium/copper interlayers, the following conclusions may be made:

1. Under monotonic loading at ambient temperatures, fracture occurred largely at the niobium/alumina interface in a brittle manner, with a mean interfacial fracture toughness of $39 \mathrm{~J} / \mathrm{m}^{2}$. This toughness is comparable with the average of the toughnesses reported for diffusion-bonded niobium/alumina, but the present bonds are far more convenient to fabricate.

2. Such failures under monotonic loading at ambient temperatures are associated with niobium/alumina interfacial separation plus small regions of interfacial copper deforming in a ductile manner and adhering to both sides of the fracture surface. Energy absorbed during the ductile tearing of the isolated copper bridges provides significant toughening to the PTLP bonded joint by contributing to the total measured fracture energy, possibly offsetting any reduction in the $\mathrm{Nb} / \mathrm{Al}_{2} \mathrm{O}_{3}$ interfacial toughness that may derive from the submonolayer segregation of $\mathrm{Cu}$ found at the interface.

3. Fracture toughness values were observed to decrease by $\sim 50 \%$ as the temperature was raised from $25^{\circ}$ to $1000^{\circ} \mathrm{C}$; this decrease was attributed, at least in part, to a reduced toughening contribution from the plastic work associated with deforming the copper phase at temperatures near its melting point.

4. Cyclic fatigue-crack trajectories were a variable combination of interfacial $(\sim 0-50 \%)$ and near-interfacial $(\sim 50-100 \%)$, in the alumina. In the predominantly near-interfacial case, the rates of fatigue-crack growth corresponded closely to those for long cracks in bulk alumina at 
the same driving force, while in the mixed interfacial/near interfacial case, crack-growth behavior in the joints exhibited somewhat lower crack-growth resistance involving higher fatigue-crack growth rates and lower fatigue thresholds.

5. Differences in the fatigue behavior are attributed to the role of extrinsic toughening mechanisms (i.e., grain bridging) in the alumina. A higher proportion of the crack path being within the alumina results in increased crack-tip shielding via grain bridging, resulting in lower near-tip driving forces and increased fatigue resistance.

6. By comparing the fracture and fatigue properties of the PTLP bonded joints to that of bulk alumina, it is concluded that the presence of joints is not detrimental to the crack growth resistance of the bonded ceramic structure in the cases where flaws sizes are in a reasonable regime for brittle materials $(<1 \mathrm{~mm})$.

\section{Acknowledgments}

The authors would like to thank Drs. James M. McNaney and Eduardo Saiz for experimental assistance and Josh Sugar for helping with fabrication of the joints.

\section{References}

${ }^{1}$ B. J. Dalgleish, A. P. Tomsia, K. Nakashima, M. R. Locatelli and A. M. Glaeser, "Low temperature routes to joining ceramics for high temperature applications," Scripta Metall. Mater., 31 [8] 1043-48 (1994).

${ }^{2}$ B. J. Dalgleish, K. Nakashima, M. R. Locatelli, A. P. Tomsia and A. M. Glaeser, "New approaches to joining ceramics for high-temperature applications," Ceram. Inter., 23 [4] 313-22 (1997).

${ }^{3} Y$. Iino, "Partial transient liquid-phase metals technique of ceramic-metal bonding," $J$. Mater. Sci. Lett., 10 [2] 104-06 (1991).

${ }^{4}$ M. R. Locatelli, A. P. Tomsia, K. Nakashima, B. J. Dalgleish and A. M. Glaeser, "New strategies for joining ceramics for high-temperature applications," Key Eng. Mater., 111-112 15790 (1995).

${ }^{5}$ R. A. Marks, D. R. Chapman, D. T. Danielson and A. M. Glaeser, "Joining of alumina via copper/niobium/copper interlayers," Acta Mater., 48 [18-19] 4425-38 (2000).

${ }^{6}$ R. A. Marks, J. D. Sugar and A. M. Glaeser, "Ceramic joining IV. Effects of processing conditions on the properties of alumina joined via $\mathrm{Cu} / \mathrm{Nb} / \mathrm{Cu}$ interlayers," J. Mater. Sci., 36 [23] 5609-24 (2001).

${ }^{7}$ M. Paulasto, G. Ceccone and S. D. Peteves, "Joining of silicon nitride via a transient liquid," Scripta Mater., 36 [10] 1167-73 (1997). 
${ }^{8}$ S. D. Peteves, M. Paulasto, G. Ceccone and V. Stamos, "The reactive route to ceramic joining: fabrication, interfacial chemistry and joint properties," Acta Mater., 46 [7] 2407-14 (1998).

${ }^{9}$ M. L. Shalz, B. J. Dalgleish, A. P. Tomsia, R. M. Cannon and A. M. Glaeser, "Ceramic joining III. Bonding of alumina via $\mathrm{Cu} / \mathrm{Nb} / \mathrm{Cu}$ interlayers," J. Mater. Sci., 29 [14] 3678-90 (1994).

${ }^{10}$ M. L. Shalz, B. J. Dalgleish, A. P. Tomsia and A. M. Glaeser, "Ceramic joining. I. Partial transient liquid-phase bonding of alumina via Cu/Pt interlayers," J. Mater. Sci., 28 [6] 1673-84 (1993).

${ }^{11}$ M. L. Shalz, B. J. Dalgleish, A. P. Tomsia and A. M. Glaeser, "Ceramic joining II. Partial transient liquid-phase bonding of alumina via $\mathrm{Cu} / \mathrm{Ni} / \mathrm{Cu}$ multilayer interlayers," J. Mater. Sci., 29 [12] 3200-08 (1994).

${ }^{12}$ L. Shaw, D. Miracle and R. Abbaschian, "Microstructure and mechanical properties of metal/oxide and metal/silicide interfaces," Acta Metall. Mater., 43 [12] 4267-79 (1995).

${ }^{13}$ N. P. O'Dowd, M. G. Stout and C. F. Shih, "Fracture toughness of alumina-niobium interfaces: experiments and analysis," Phil. Mag. A, 66 [6] 1037-64 (1992).

${ }^{14} \mathrm{M}$. Turwitt, G. Elssner and G. Petzow, "Manufacturing and mechanical properties of interfaces between sapphire and niobium," J. De Physique, 46 C4-123-C4-27 (1985).

${ }^{15} \mathrm{G}$. Elssner, T. Suga and M. Turwitt, "Fracture of ceramic-to-metal interfaces," J. De Physique, 46 C4-597-C4-612 (1985).

${ }^{16}$ D. Korn, G. Elssner, H. F. Fischmeister and M. Rühle, "Influence of interface impurities on the fracture energy of UHV bonded niobium-sapphire bicrystals," Acta Metall. Mater., 40 S355-S60 (1992).

${ }^{17}$ G. Elssner, D. Korn and M. Rühle, "The influence of interface impurities on fracture energy of UHV diffusion bonded metal-ceramic bicrystals," Scripta Metall. Mater., 31 [8] 1037 42 (1994).

${ }^{18}$ D. Korn, G. Elssner, R. Cannon and M. Rühle, "Fracture properties of interfacially doped $\mathrm{Nb}-\mathrm{Al}_{2} \mathrm{O}_{3}$ bicrystals I, Fracture characteristics," Acta Mater., in press (2002).

${ }^{19}$ R. M. Cannon, D. Korn, G. Elssner and M. Rühle, "Fracture properties of interfacially doped $\mathrm{Nb}-\mathrm{Al}_{2} \mathrm{O}_{3}$ bicrystals II, Relation of interfacial bonding, chemistry and local plasticity," Acta Mater., in press (2002).

${ }^{20}$ J. R. Rice and G. C. Sih, "Plane problems of cracks in dissimilar media," J. App. Mech., 32 418-23 (1965).

${ }^{21}$ G. C. Sih and J. R. Rice, "The bending of plates of dissimilar materials with cracks," $J$. App. Mech., 31 477-82 (1964).

${ }^{22}$ J. R. Rice, "Elastic fracture mechanics concepts for interfacial cracks," J. App. Mech., 55 [1] 98-103 (1988).

${ }^{23} \mathrm{~J}$. Dundurs, "Edge-bonded dissimilar orthogonal elastic wedges under normal and shear loading," J. App. Mech., 36 650-52 (1969).

${ }^{24} \mathrm{Z}$. Suo and J. W. Hutchinson, "Sandwich test specimens for measuring interface crack toughness," Mater. Sci. Eng., A107 135-43 (1989).

${ }^{25} \mathrm{~J}$. W. Hutchinson, M. E. Mear and J. R. Rice, "Crack paralleling and interface between dissimilar materials," J. App. Mech., 54 [4] 828-32 (1987).

${ }^{26}$ T. L. Becker, J. M. McNaney, R. M. Cannon and R. O. Ritchie, "Limitations on the use of the mixed-mode delaminating beam test specimen: Effect of the size of the region of Kdominance," Mech. Mater., 25 [4] 291-308 (1997). 
${ }^{27}$ J. W. Hutchinson and Z. Suo, "Mixed mode cracking in layered materials," Adv. App. Mech., 29 63-191 (1992).

${ }^{28}$ C. F. Shih, "Cracks on bimaterial interfaces: elasticity and plasticity aspects," Mater. Sci. Eng., A143 [1-2] 77-90 (1991).

${ }^{29}$ R. O. Ritchie, R. M. Cannon, B. J. Dalgleish, R. H. Dauskardt and J. M. McNaney, "Mechanics and mechanisms of crack growth at or near ceramic-metal interfaces: interface engineering strategies for promoting toughness," Mater. Sci. Eng., A166 [1-2] 221-35 (1993).

${ }^{30}$ Y. Murakami, Stress Intensity Factors Handbook. 1st ed. Pergamon Press, Elmsford, New York, (1987).

${ }^{31}$ J. M. McNaney, R. Havens and R. O. Ritchie, "Elastic compliance of the compact tension specimen comprising two linear-elastic materials bonded with a thin layer," J. Test. Eval., 25 [1] 28-35 (1997).

${ }^{32}$ J. M. McNaney, R. M. Cannon and R. O. Ritchie, "Fracture and fatigue crack growth along aluminum-alumina interfaces," Acta Mater., 44 [12] 4713-28 (1996).

${ }^{33}$ W. F. Deans and C. E. Richards, "A simple and sensitive method of monitoring crack and load in compact fracture mechanics specimens using strain gages," J. Test. Eval., 7 [3] 147-54 (1979).

${ }^{34} \mathrm{P}$. J. Cumpson and M. P. Seah, "Elastic scattering corrections in AES and XPS. II. Estimating attenuation lengths and conditions required for their valid use in overlayer/substrate experiments," Surf. Interface Anal., 25 [6] 430-46 (1997).

${ }^{35}$ L. E. Davis, N. C. MacDonald, P. W. Palmberg, G. E. Riach and R. E. Weber, Handbook of Auger Electron Spectroscopy. Perkin-Elmer Corporation, Eden Prairie, MN, (1978).

${ }^{36}$ M. P. Seah, "Quantification of AES and XPS"; pp. 201-55 in Practical Surface Analysis by Auger and X-Ray Photoelectron Spectroscopy. Edited by D. Briggs and M. P. Seah. J. Wiley \& Sons, New York, 1990.

${ }^{37}$ R. O. Ritchie, "Mechanisms of fatigue-crack propagation in ductile and brittle solids," Int. J. Fract., 100 [1] 55-83 (1999).

${ }^{38}$ J. J. Kruzic, J. M. McNaney, R. M. Cannon and R. O. Ritchie, "Effects of plastic constraint on the cyclic and static fatigue behavior of metal/ceramic layered structures," Mech. Mater., in press (2002).

${ }^{39}$ R. K. Nekkanti and D. M. Dimiduk, "Ductile-phase toughening in niobium-niobium silicide powder processed composites"; pp. 175-82 in MRS Symposium Proceedings, Vol. 194, Intermetallic Matrix Composites. Edited by D. L. Anton, P. L. Martin, D. B. Miracle and R. McMeeking. Materials Research Society, Pittsburgh, PA, 1990.

${ }^{40}$ J. D. Sugar, J. T. McKeown, R. M. Marks and A. M. Glaeser, "Liquid-film assisted formation of alumina/niobium interfaces," J. Am. Ceram. Soc., in press (2002).

${ }^{41}$ G. Elssner, S. Riedel and R. Pabst, "Fractography and fracture paths in ceramic-metal composites," Pract. Metall., 12 [5] 234-43 (1975).

${ }^{42}$ G. Kiessler, D. Korn and G. Elssner, "Metallographic and fracture surface investigations of metal-ceramic bicrystals," Pract. Metall., 29 [12] 597-610 (1992).

${ }^{43}$ C. D. Bencher, A. Sakaida, K. T. Venkateswara Rao and R. O. Ritchie, "Toughening mechanisms in ductile niobium-reinforced niobium aluminide $\left(\mathrm{Nb} / \mathrm{Nb}_{3} \mathrm{Al}\right)$ in situ composites," Metall. Mater. Trans., 26A [8] 2027-33 (1995).

${ }^{44}$ B. D. Flinn, M. Rühle and A. G. Evans, "Toughening in composites of $\mathrm{Al}_{2} \mathrm{O}_{3}$ reinforced with Al," Acta Metall., 37 [11] 3001-06 (1989). 
${ }^{45}$ V. V. Krstic, P. S. Nicholson and R. G. Hoagland, "Toughening of glasses by metal particles," J. Am. Ceram. Soc., 64 [9] 499-504 (1981).

${ }^{46}$ L. Murugesh, K. T. Venkateswara Rao and R. O. Ritchie, "Crack growth in a ductilephase-toughened $\mathrm{Nb} / \mathrm{Nb}_{3} \mathrm{Al}$ in situ intermetallic composite under monotonic and cyclic loading," Scripta Metall. Mater., 29 [8] 1107-12 (1993).

${ }^{47}$ L. S. Sigl, P. A. Mataga, B. J. Dalgleish, R. M. McMeeking and A. G. Evans, "On the toughness of brittle materials reinforced with a ductile phase," Acta Metall., 36 [4] 945-53 (1988).

${ }^{48}$ M. F. Ashby, F. J. Blunt and M. Bannister, "Flow characteristics of highly constrained metal wires," Acta Metall., 37 [7] 1847-57 (1989).

${ }^{49}$ P. L. Swanson, C. J. Fairbanks, B. R. Lawn, Y.-W. Mai and B. J. Hockey, "Crackinterface grain bridging as a fracture resistance mechanism in ceramics: I, Experimental study on alumina," J. Am. Ceram. Soc., 70 [4] 279-89 (1987).

${ }^{50}$ Y.-W. Mai and B. R. Lawn, "Crack-interface grain bridging as a fracture resistance mechanism in ceramics: II, Theoretical fracture mechanics model," J. Am. Ceram. Soc., 70 [4] 289-94 (1987).

${ }^{51}$ S. J. Bennison and B. R. Lawn, "Role of interfacial grain-bridging sliding friction in the crack-resistance and strength properties of nontransforming ceramics," Acta Metall., 37 [10] 265971 (1989).

${ }^{52}$ A. G. Evans, J. W. Hutchinson and Y. Wei, "Interface adhesion: effects of plasticity and segregation," Acta Mater., 47 [15] 4093-113 (1999).

${ }^{53}$ R. M. Cannon, V. Jarayam, B. J. Dalgleish and R. M. Fisher, "Microstructural and chemical components of ceramic-metal interfacial fracture energies"; pp. 121-26 in MRS Symposium Proceedings, Vol. 72, Electronic Packaging Materials Science II. Edited by R. J. Nemanich, P. S. Ho and S. S. Lau. Materials Research Society, Pittsburgh, PA, 1986.

${ }^{54}$ P. Gumbsch and R. M. Cannon, "Atomistic aspects of brittle fracture," Mater. Res. Soc. Bull., 25 [5] 15-20 (2000).

${ }^{55}$ C. F. Shih and R. J. Asaro, "Elastic-plastic analysis of cracks on bimaterial interfaces: Part II - Structure of small-scale yielding fields," J. App. Mech., 56 [4] 763-79 (1989).

${ }^{56} \mathrm{C}$. F. Shih, "Relationships between the J-integral and the crack opening displacement for stationary and extending cracks," J. Mech. Phys. Solids, 29 [4] 305-26 (1981).

${ }^{57}$ Z. Suo, C. F. Shih and A. G. Varias, "A theory for cleavage cracking in the presence of plastic flow," Acta Metall. Mater., 41 [5] 1551-57 (1993).

${ }^{58} \mathrm{Y}$. Wei and J. W. Hutchinson, "Models of interface separation accompanied by plastic dissipation at multiple scales," Int. J. Fract., 95 [1-4] 1-17 (1999).

${ }^{59}$ K. T. Venkateswara Rao, G. R. Odette and R. O. Ritchie, "On the contrasting role of ductile-phase reinforcements in the fracture toughness and fatigue-crack propagation behavior of $\mathrm{TiNb} / \gamma$-TiAl intermetallic matrix composites," Acta Metall. Mater., 40 [2] 353-61 (1992).

${ }^{60}$ C. J. Gilbert, R. N. Petrany, R. O. Ritchie, R. H. Dauskardt and R. W. Steinbrech, "Cyclic fatigue in monolithic alumina: mechanisms for crack advance promoted by frictional wear of grain bridges," J. Mater. Sci., 30 [3] 643-54 (1995).

${ }^{61}$ R. F. Cook and A. G. Schrott, "Calcium segregation to grain boundaries in alumina," J. Am. Ceram. Soc., 71 [1] 50-58 (1988).

${ }^{62}$ S. Lathabai, J. Rödel and B. Lawn, "Cyclic fatigue from frictional degradation at bridging grains in alumina," J. Am. Ceram. Soc., 74 [6] 1348-60 (1991).

${ }^{63}$ R. D. Geraghty, J. C. Hay and K. W. White, "Fatigue degradation of the crack wake zone in monolithic alumina," Acta Mater., 47 [4] 1345-53 (1999). 
${ }^{64}$ F. Guiu, M. Li and M. J. Reece, "Role of crack-bridging ligaments in the cyclic fatigue behavior of alumina," J. Am. Ceram. Soc., 75 [11] 2976-84 (1992).

${ }^{65}$ R. H. Dauskardt, "A frictional-wear mechanism for fatigue-crack growth in grain bridging ceramics," Acta Metall. Mater., 41 [9] 2765-81 (1993).

${ }^{66}$ S. Suresh and R. O. Ritchie, "Propagation of short fatigue cracks," Int. Metals Rev., 29 [6] 445-76 (1984).

${ }^{67}$ A. Buch, Pure metals properties: a scientific - technical handbook. ASM International, Materials Park, OH, (1999). 


\section{Figure Captions}

Figure 1: Micrograph showing the microstructure of AD995 alumina. Sample was thermally etched in air at $1550^{\circ} \mathrm{C}$ for 30 minutes to reveal grain boundaries.

Figure 2: Interfacial fracture toughness of PTLP bonded joints as a function of temperature. Elevated temperature tests were performed in gettered argon.

Figure 3: Matching micrographs of the same region of the (a) niobium and (b) alumina side of the fast fracture surfaces. The deformed copper regions are adhered to both sides of the fracture surface while $\mathrm{Nb}_{5} \mathrm{Si}_{3}$ particles are only on alumina side. Grain boundary grooving is evident in the alumina, with matching imprints appearing in the niobium. Direction of crack propagation was left to right with respect to the micrograph.

Figure 4: Micrograph of a large $\mathrm{Nb}_{5} \mathrm{Si}_{3}$ particle on the alumina side of the fast fracture surface that was used for quantitative EDS measurements. Direction of crack propagation was left to right with respect to the micrograph.

Figure 5: Fatigue-crack growth rates for PTLP bonded sandwich specimens. Individual symbols correspond to different individual samples. Higher fatigue thresholds were measured for samples with more alumina grain pullout during fatigue-crack growth.

Figure 6: Micrographs of fatigue fracture surfaces showing (a) 50\% and (b) 100\% alumina grain pullout. For the latter case, fatigue-crack propagation was almost entirely in the alumina. Direction of crack propagation was left to right with respect to the micrograph.

Figure 7: Matching micrographs of the same region of the (a) niobium and (b) alumina side of the fatigue fracture surfaces. Deformed copper regions appear flattened with some separation of the alumina/copper interface visible. Matching imprints of the alumina grain boundaries can be seen in the niobium. Direction of crack propagation was left to right with respect to the micrograph.

Figure 8: R-curve measured for Coors AD995 alumina demonstrating rising crack-growth resistance with crack extension. Data shown were collected from a fatigue pre-cracked $\mathrm{C}(\mathrm{T})$ sample where the pre-crack was grown only $230 \mu \mathrm{m}$ from the machined notch to minimize the initial crack length.

Figure 9: Fatigue-crack growth rates for short $\left(\Delta a_{f}<2 \mathrm{~mm}\right)$ fatigue cracks in Coors AD995 alumina where grain bridging was limited due to the short wake behind the crack tip. Note that the short crack data compare favorably with the data for PTLP joints where alumina grain bridging was limited due to a partial $(\sim 50 \%)$ interfacial crack path. 
Table I. Material Properties ${ }^{\#}$

\begin{tabular}{lcccc}
\hline Material & Young's Modulus & Poisson's Ratio & Shear Modulus & CTE $\left(20\right.$ to $\left.1000^{\circ} \mathrm{C}\right)$ \\
\hline $\mathrm{Al}_{2} \mathrm{O}_{3}$ & $372 \mathrm{GPa}$ & 0.22 & $152 \mathrm{GPa}$ & $8.2 \times 10^{-6}{ }^{\circ} \mathrm{C}^{-1}$ \\
Niobium & $103 \mathrm{GPa}$ & 0.37 & $37.5 \mathrm{GPa}$ & $7.9 \times 10^{-6}{ }^{\circ} \mathrm{C}^{-1}$ \\
Copper & $125 \mathrm{GPa}$ & 0.34 & $46.4 \mathrm{GPa}$ & $20.3 \times 10^{-6}{ }^{\circ} \mathrm{C}^{-1}$ \\
\hline
\end{tabular}

\# Properties for AD995 alumina were provided by Coors while properties for pure metals were taken from ref. 67.

Table II. Dundurs' Parameters for Elastic Mismatch

\begin{tabular}{lcc}
\hline Material1/Material2 & $\alpha$ & $\beta$ \\
\hline $\mathrm{Al}_{2} \mathrm{O}_{3} /$ Niobium & 0.532 & 0.153 \\
$\mathrm{Al}_{2} \mathrm{O}_{3} /$ Copper & 0.469 & 0.152 \\
Niobium/Copper & -0.084 & -0.001 \\
\hline
\end{tabular}

Table III. Auger Spectroscopy of Fracture Surface

\begin{tabular}{lcccc}
\hline \multicolumn{1}{c}{ Side } & $\mathrm{O}(\mathrm{ML})$ & $\mathrm{Al}$ & $\mathrm{Cu}(\mathrm{ML})$ & $\mathrm{Nb}$ \\
\hline $\mathrm{Nb}$ & $0.52 \pm 0.30$ & $\sim 0$ & $0.73 \pm 0.26$ & Major \\
$\mathrm{Al}_{2} \mathrm{O}_{3}$ & Major & Major & $\sim 0$ & Trace \\
\hline
\end{tabular}




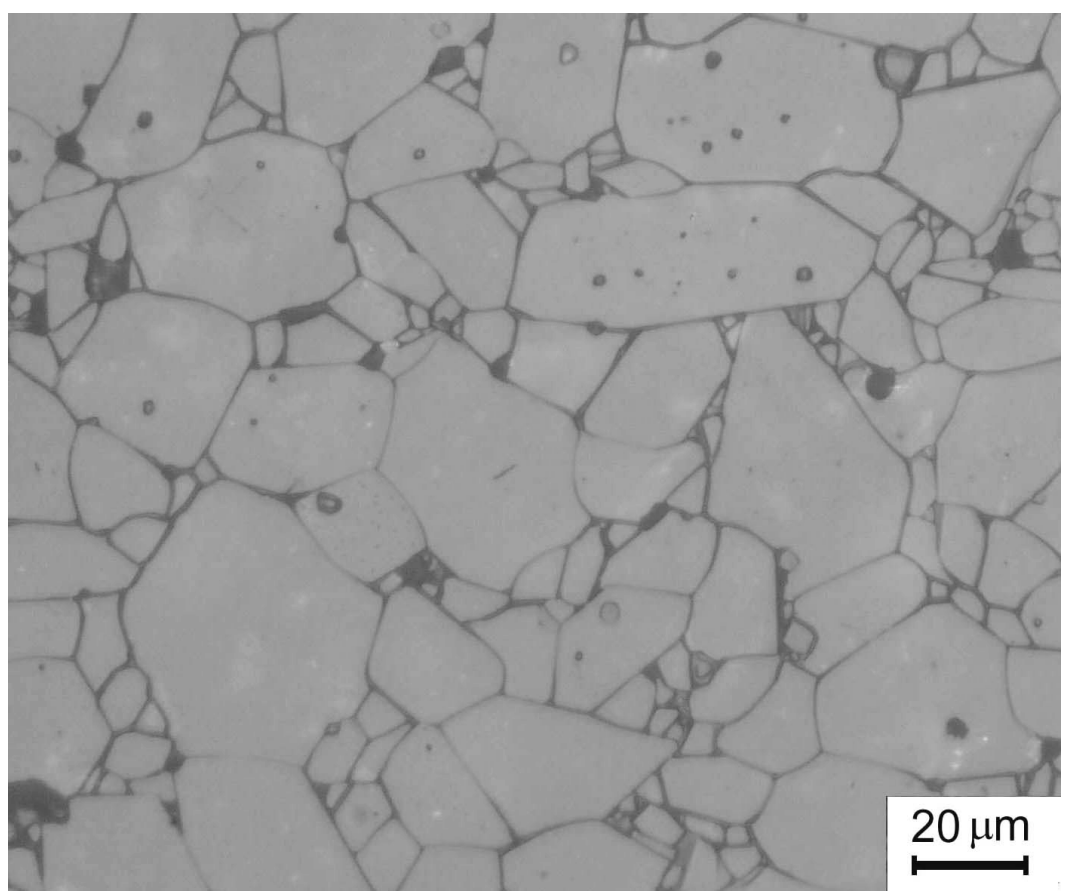

Figure 1: Micrograph showing the microstructure of AD995 alumina. Sample was thermally etched in air at $1550^{\circ} \mathrm{C}$ for 30 minutes to reveal grain boundaries. 


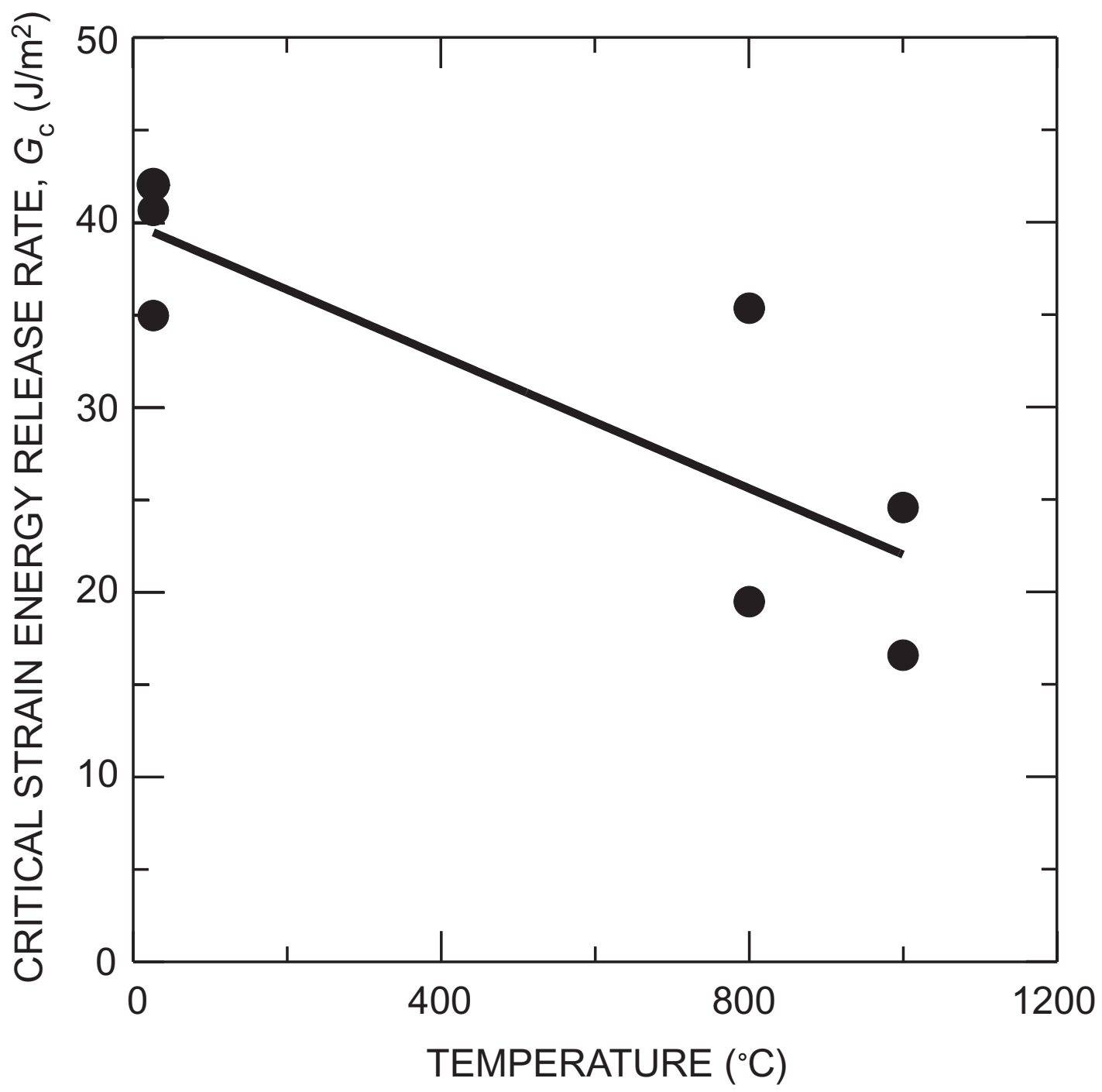

Figure 2: Interfacial fracture toughness of PTLP bonded joints as a function of temperature. Elevated temperature tests were performed in gettered argon. 

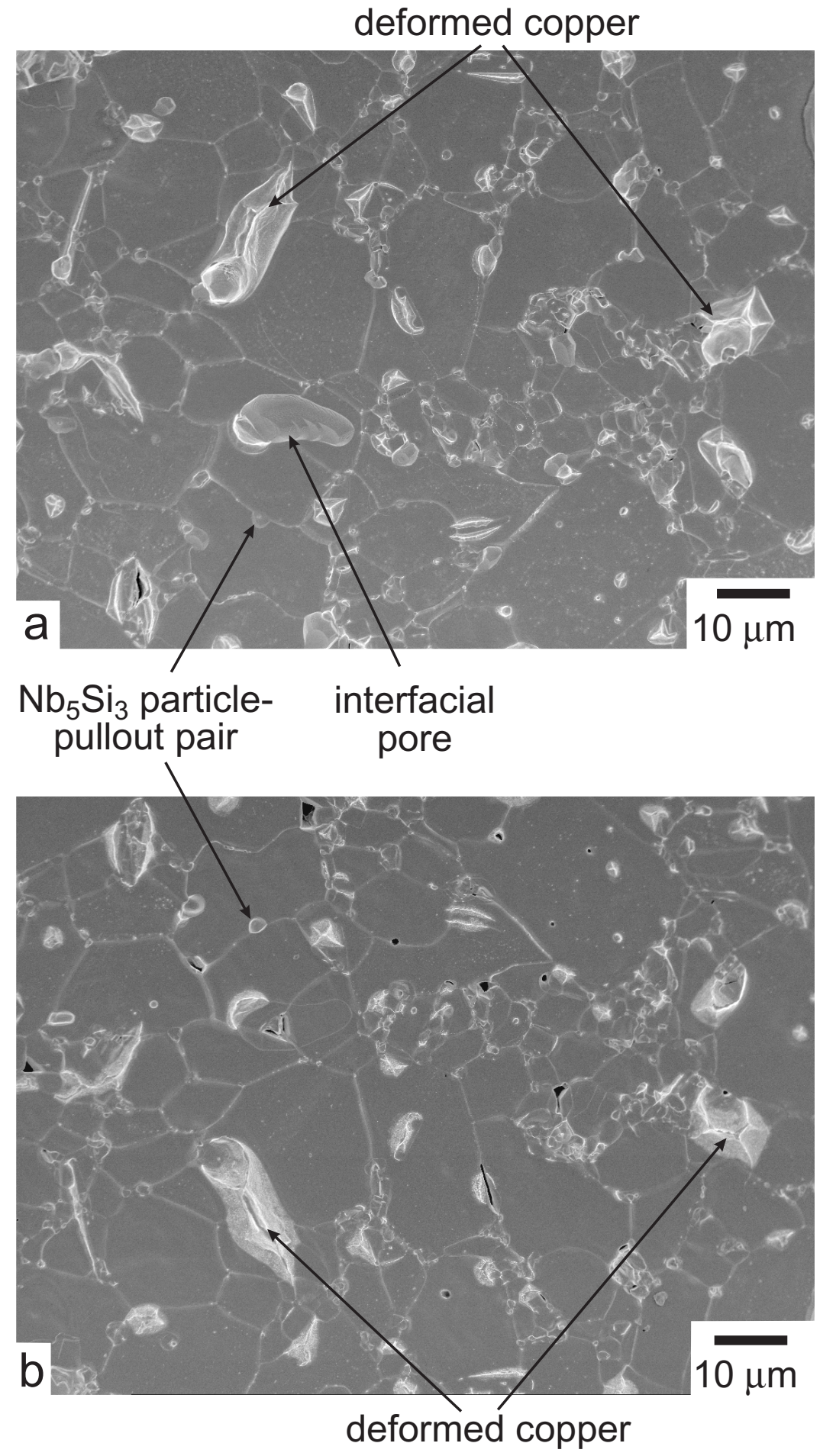

Figure 3: Matching micrographs of the same region of the (a) niobium and (b) alumina side of the fast fracture surfaces. The deformed copper regions are adhered to both sides of the fracture surface while $\mathrm{Nb}_{5} \mathrm{Si}_{3}$ particles are only on alumina side. Grain boundary grooving is evident in the alumina, with matching imprints appearing in the niobium. Direction of crack propagation was left to right with respect to the micrograph. 


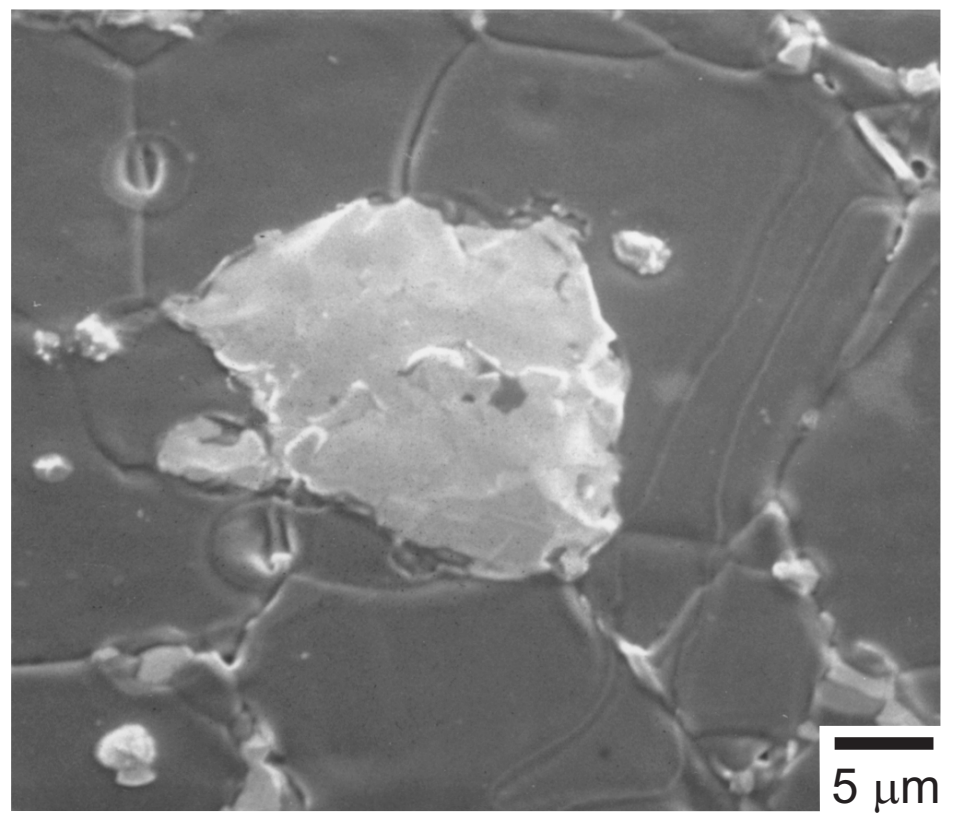

Figure 4: Micrograph of a large $\mathrm{Nb}_{5} \mathrm{Si}_{3}$ particle on the alumina side of the fast fracture surface that was used for quantitative EDS measurements. Direction of crack propagation was left to right with respect to the micrograph. 


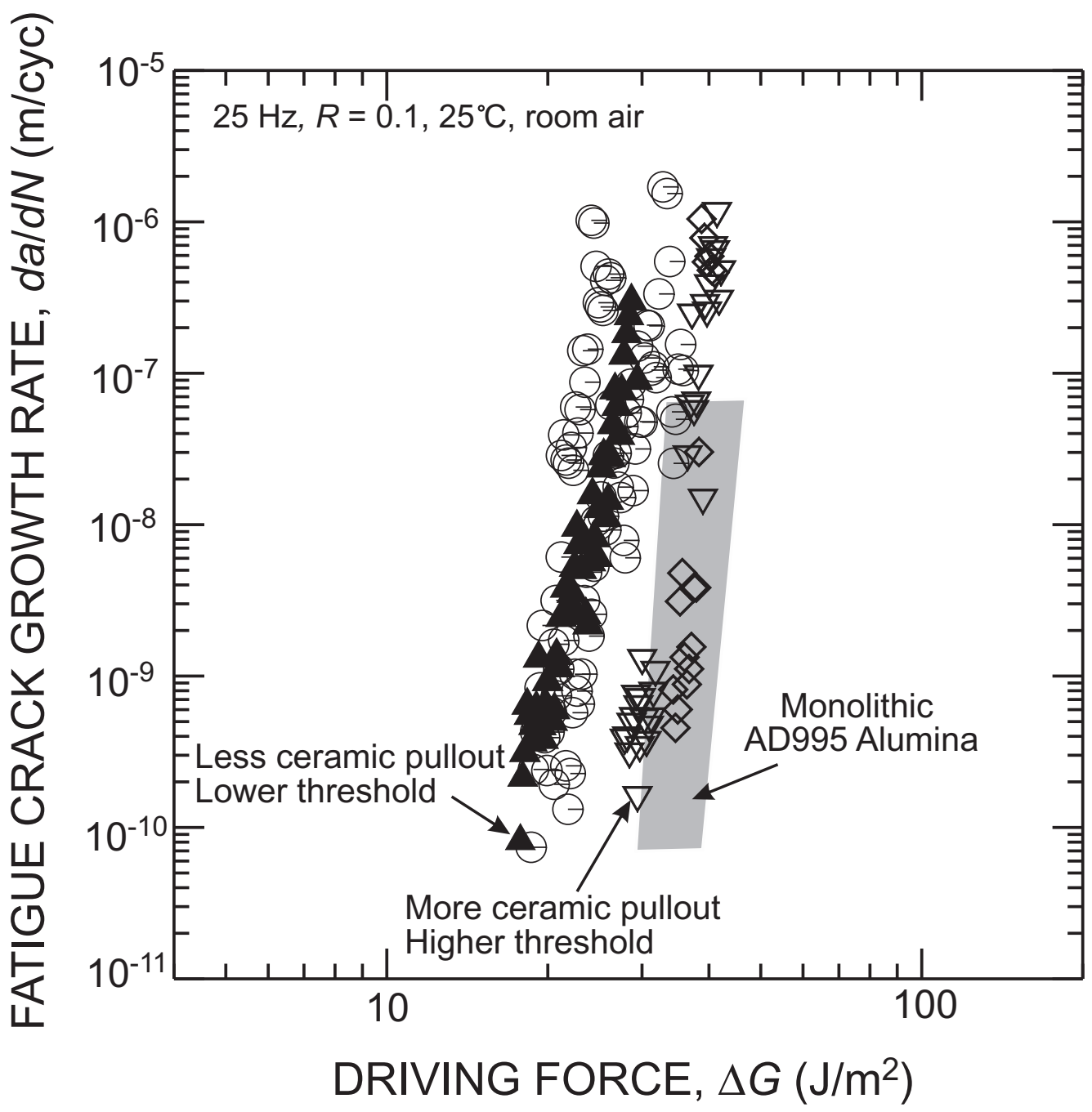

Figure 5: Fatigue-crack growth rates for PTLP bonded sandwich specimens. Individual symbols correspond to different individual samples. Higher fatigue thresholds were measured for samples with more alumina grain pullout during fatiguecrack growth. 

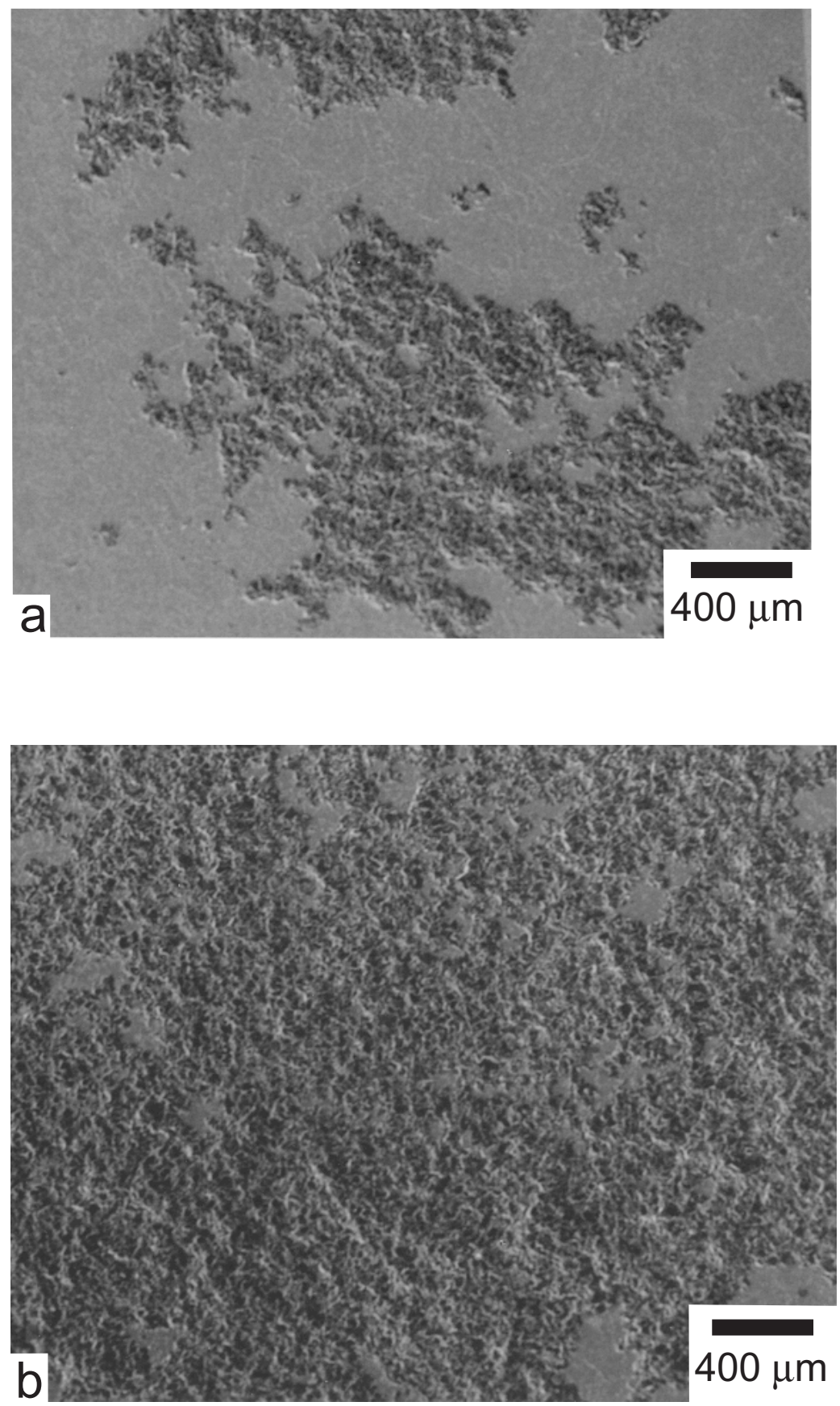

Figure 6: Micrographs of fatigue fracture surfaces showing (a) 50\% and (b) 100\% alumina grain pullout. For the latter case, fatigue-crack propagation was almost entirely in the alumina. Direction of crack propagation was left to right with respect to the micrograph. 


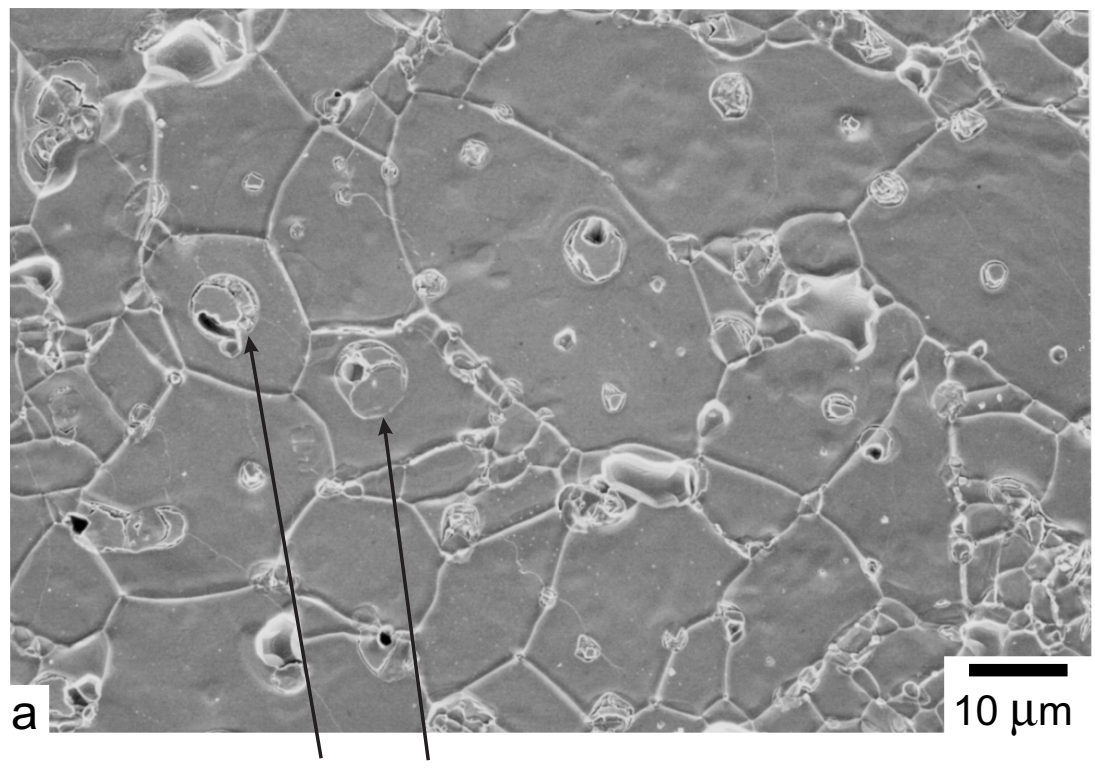

\section{deformed \\ copper}

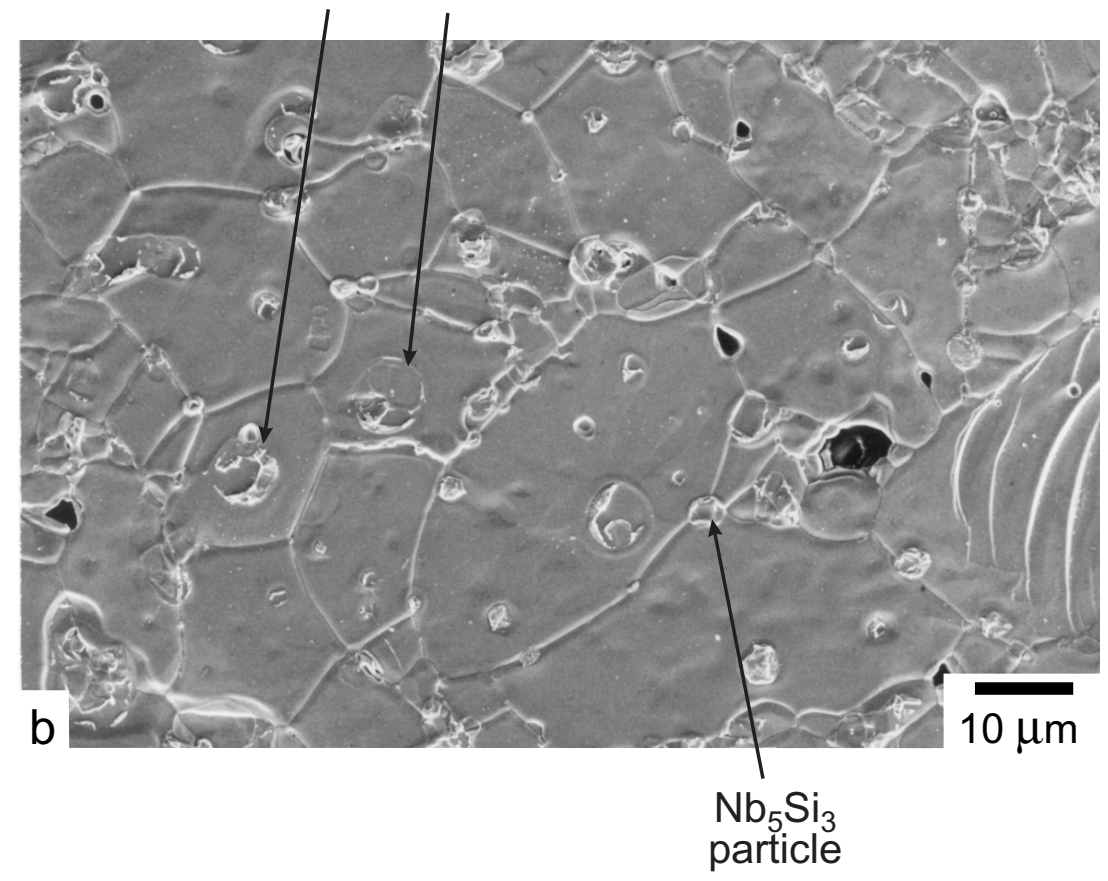

Figure 7: Matching micrographs of the same region of the (a) niobium and (b) alumina side of the fatigue fracture surfaces. Deformed copper regions appear flattened with some separation of the alumina/copper interface visible. Matching imprints of the alumina grain boundaries can be seen in the niobium. Direction of crack propagation was left to right with respect to the micrograph. 


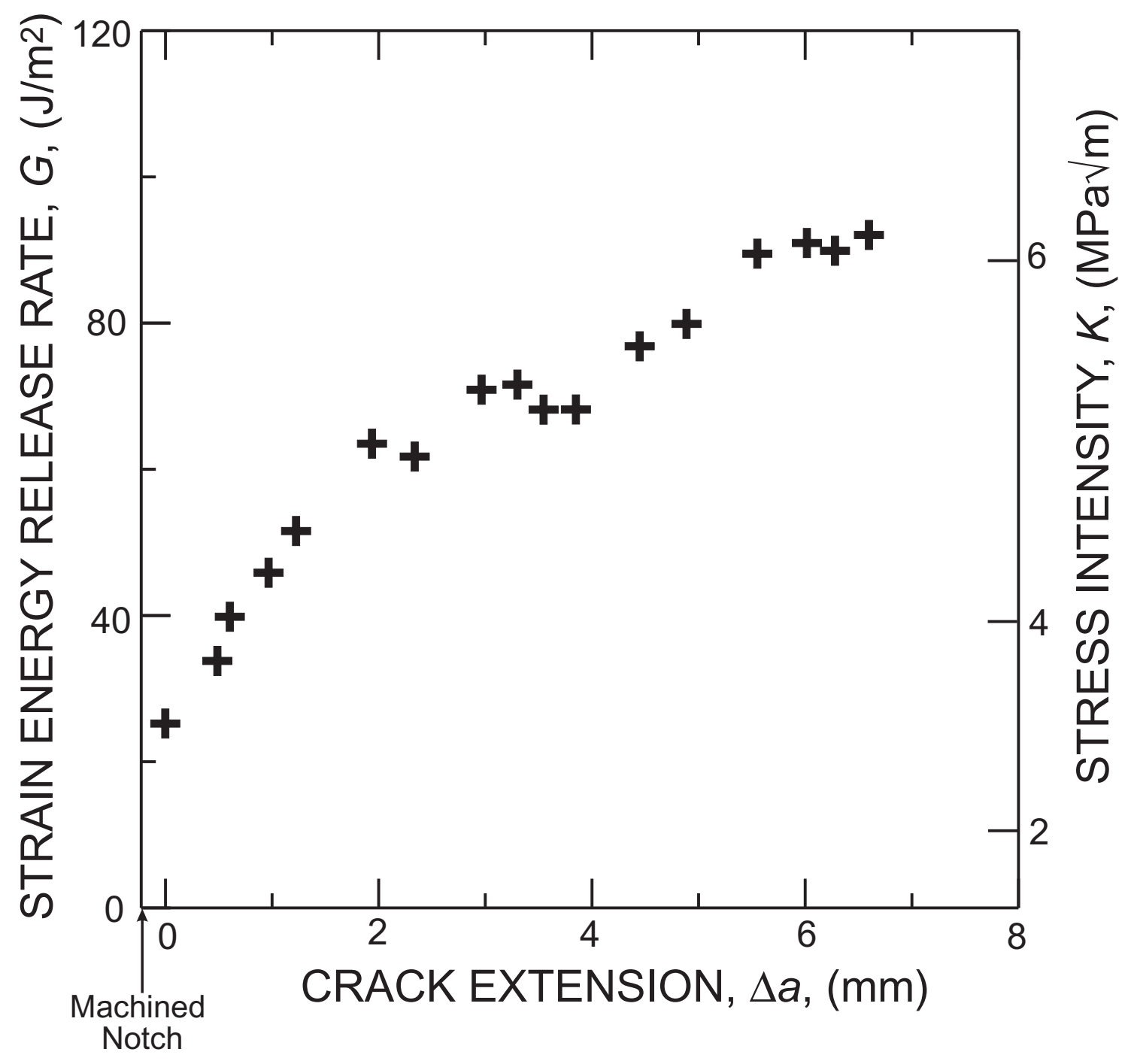

Figure 8: R-curve measured for Coors AD995 alumina demonstrating rising crackgrowth resistance with crack extension. Data shown were collected from a fatigue pre-cracked $\mathrm{C}(\mathrm{T})$ sample where the pre-crack was grown only $230 \mu \mathrm{m}$ from the machined notch to minimize the initial crack length. 


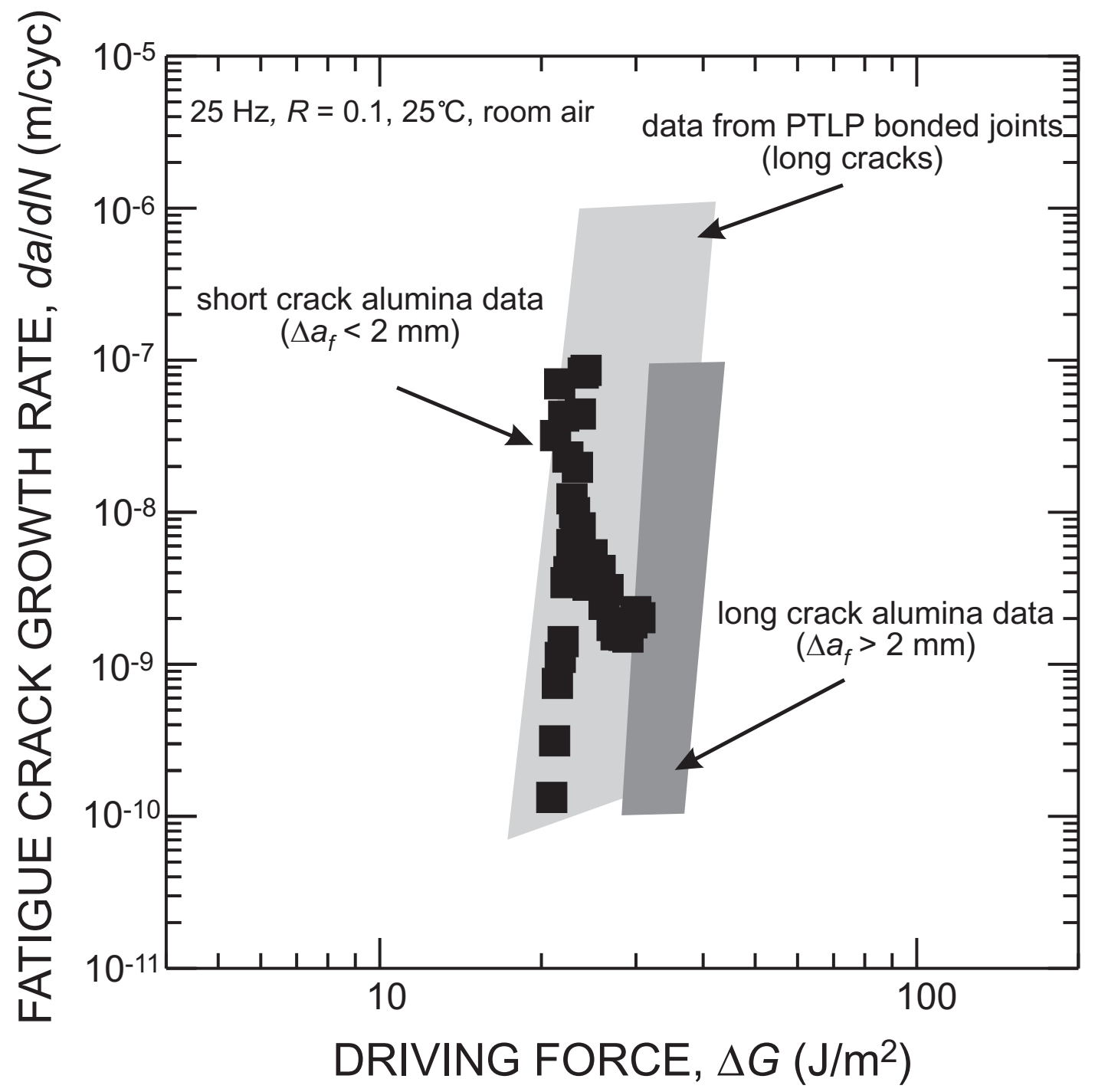

Figure 9: Fatigue-crack growth rates for short $\left(\Delta a_{f}<2 \mathrm{~mm}\right)$ fatigue cracks in Coors AD995 alumina where grain bridging was limited due to the short wake behind the crack tip. Note that the short crack data compare favorably with the data for PTLP joints where alumina grain bridging was limited due to a partial $(\sim 50 \%)$ interfacial crack path. 